\title{
CONSUMER SENTIMENT: \\ ITS RATIONALITY AND USEFULNESS IN FORECASTING EXPENDITURE - EVIDENCE FROM THE MICHIGAN MICRO DATA
}

\author{
Nicholas S. Souleles \\ Working Paper 8410 \\ http://www.nber.org/papers/w8410 \\ NATIONAL BUREAU OF ECONOMIC RESEARCH \\ 1050 Massachusetts Avenue \\ Cambridge, MA 02138 \\ August 2001
}

For helpful comments I thank Martin Browning, Chris Carroll, Roger Ferguson, Todd Sinai, Sarah Tanner, and seminar participants at Chicago, Princeton, Tilburg, the Federal Reserve Board of Governors, McMaster, York, the NBER summer workshop and the Wharton macro lunch. I am very grateful to Richard Curtin for providing data and feedback, and to Hoon Ping Teo for excellent research assistance. Of course, none of these people is responsible for any errors herein. The views expressed herein are those of the author and not necessarily those of the National Bureau of Economic Research.

(C) 2001 by Nicholas S. Souleles. All rights reserved. Short sections of text, not to exceed two paragraphs, may be quoted without explicit permission provided that full credit, including $\mathbb{C}$ notice, is given to the source. 
Consumer Sentiment: Its Rationality and Usefulness in Forecasting Expenditure

- Evidence from the Michigan Micro Data

Nicholas S. Souleles

NBER Working Paper No. 8410

August 2001

JEL No. E21

\begin{abstract}
This paper provides one of the first comprehensive analyses of the household data underlying the Michigan Index of Consumer Sentiment. This data is used to test the rationality of consumer expectations and to assess their usefulness in forecasting expenditure. The results can also be interpreted as characterizing the shocks that have hit different types of households over time. Expectations are found to be biased, at least ex post, in that forecast errors do not average out even over a sample period lasting almost 20 years. People underestimated the disinflation of the early 1980's and in the 1990's, and generally appear to underestimate the amplitude of business cycles. Forecasts are also inefficient, in that people's forecast errors are correlated with their demographic characteristics and/or aggregate shocks did not hit all people uniformly.

Further, sentiment is found to be useful in forecasting future consumption, even controlling for lagged consumption and macro variables like stock prices. This excess sensitivity is counter to the permanent income hypothesis [PIH]. Higher confidence is correlated with less saving, consistent with precautionary motives and increases in expected future resources. Some of the rejection of the PIH is found to be due to the systematic demographic components in forecast errors. But even after controlling for these components, some excess sensitivity persists. More broadly, these results suggest that empirical implementations of forward-looking models need to better account for systematic heterogeneity in forecast errors.
\end{abstract}

Nicholas S. Souleles

Finance Department

Wharton School

2300 SH-DH

University of Pennsylvania

Philadelphia, PA 19104-6367

and NBER 
Debate over the usefulness of consumer sentiment surveys in forecasting economic activity began soon after their introduction in the 1940's. The possibility that a decline in consumer confidence helped cause or worsen the 1990-91 recession renewed interest in the debate. Most recent studies of sentiment have focused on the time series relationship between aggregate consumption and the two main aggregate indices of sentiment, the Michigan Index of Consumer Sentiment [ICS] and the Conference Board Consumer Confidence Index. This paper, by contrast, provides perhaps the first comprehensive analysis of the household-level data that underlies the ICS, the Michigan Survey of Consumer Attitudes and Behavior [CAB]. The attention that the ICS receives, from policymakers, academics, and the business community, itself warrants an analysis of the underlying data. There are also a number of methodological advantages to such an analysis.

First, with micro data one can assess the rationality of household expectations. Most previous rationality tests have limited their focus to inflation expectations, just one of the many variables that will be examined here. Also, the tests have generally used aggregated data, or at most short micro panels. But when agents' information sets differ, aggregation can lead to spurious rejections of rationality. The average of rational individual forecasts need not be a rational forecast conditional on any single information set (Keane and Runkle [1990]). And even if individual forecasts are perfectly rational, it might take a long time -- perhaps multiple business cycles -- for forecast errors to average out. Hence to test rationality it is important to use micro data on expectations over long sample periods. Unfortunately such data is not usually available. The $\mathrm{CAB}$ survey, however, is unique in containing almost 20 years of monthly household expectations data. This paper exploits its panel aspect to test more cleanly than usual whether expectations are unbiased and efficient. The results can also be interpreted as explicitly 
characterizing the shocks that have hit different types of households over time, across business cycles and policy regimes. In addition to its welfare implications, such a characterization is of methodological interest, because both theoretical and empirical models are generally sensitive to the assumptions made about shock processes. In particular, many models assume that "aggregate" shocks affect all households uniformly.

Second, this paper assesses whether the sentiment surveys are useful in predicting behavior, specifically household spending. The canonical permanent income (or life-cycle) hypothesis $[\mathrm{PIH}]$ provides a natural setting for this assessment. One of the central implications of the PIH is that current consumption should incorporate all the information available to an agent. However the econometrician does not independently observe the contents of agents' information sets, so tests of this implication usually need to make strong assumptions, inferring agents' expectations econometrically. This paper instead uses the direct survey data on expectations in the $\mathrm{CAB}$. This data is matched, using a rich set of demographic variables, with the Consumer Expenditure Survey [CEX], which has the most comprehensive micro data on expenditure. The resulting test is whether the expectations data contain additional information, beyond that in current consumption, that helps predict future consumption. Previous studies of the excess sensitivity of consumption to sentiment have used aggregate sentiment data, but aggregation can induce spurious excess sensitivity even when there is none at the micro level (Attanasio and Weber [1995]). The construction of the ICS is not consistent with the construction of aggregate consumption. For instance the ICS is an equal-weighted average of the sentiment of the $\mathrm{CAB}$ survey respondents, which ignores differences in the scale of consumption across respondents.

With micro data one can also more readily investigate the sources of any excess sensitivity. One alternative hypothesis that has not previously received much scrutiny is that 
forecast errors might not be classical, but rather contain systematic components correlated with the excess sensitivity regressor. For instance, over the sample period high income households might on average have been optimistic about the future, and might have happened to receive disproportionately positive shocks. In this case increases in their consumption, and so a positive correlation between consumption and sentiment, would not be inconsistent with the PIH. More broadly, Chamberlain [1984] and others have pointed out that systematic components of forecast errors are a potential problem in estimating any consumption Euler-equation, or generally any rational expectations (or forward-looking) model, in a short panel. Because direct measures of households' forecast errors are available here, it is possible to test this point directly.

Third, the aggregate ICS ignores potentially useful information available in the micro $\mathrm{CAB}$ data. As already noted, the ICS neglects the cross-sectional distribution of sentiment. This distribution might be useful in predicting the expenditure of different groups of consumers, or even aggregate expenditure insofar as the relation between expenditure and sentiment at the household level does not aggregate up. In the ICS a given respondent's sentiment is in turn the sum of her answers to five very different survey questions, which makes it hard to interpret. This paper examines, separately for each question, whether over a long series of cross-sections the survey responses help forecast household spending. This examination also addresses one perennial question in the time-series literature: Does sentiment provide information useful in forecasting, above and beyond the information contained by other available macro variables like stock prices? By controlling for time effects in the micro data, one can exploit purely crosssectional variation that is perforce orthogonal to any macro variable.

To preview the results, expectations appear to be biased, at least ex post, in that forecast errors do not average out even over a sample period lasting almost 20 years. This bias is not 
constant over time; it is related to the inflation regime and the business cycle. People underestimated the disinflation of the early 1980's and in the 1990's, and generally appear to underestimate the amplitude of business cycles. Forecasts are also inefficient, in that people's forecast errors are correlated with their demographic characteristics and/or aggregate shocks did not hit all people uniformly. For instance, during expansions high income households received relatively good shocks, but low income households continued to receive somewhat negative shocks, consistent with ongoing, unexpected skill-biased technical change. Further, sentiment is useful in forecasting future consumption, even beyond lagged consumption and other macro variables, counter to the PIH. Higher confidence is correlated with less saving, consistent with precautionary motives and increases in expected future resources. Some of the rejection of the $\mathrm{PIH}$ is found to be due to the systematic demographic components in forecast errors. But even after controlling for these components, some excess sensitivity persists. More broadly, because forecast errors are correlated with household demographic characteristics, they will be correlated with many regressors of interest in forward-looking models. This suggests that systematic heterogeneity in forecast errors is in practice a general and serious problem.

The paper begins by surveying related studies in Section I. Section II describes the data and Section III, the econometrics. Section IV tests the rationality of expectations and more generally characterizes the properties of forecast errors. Section V tests whether sentiment helps forecast expenditure, and if so whether this is due to systematic demographic components in forecast errors. Section VI concludes.

\section{Related Studies}

Most tests of the rationality of surveyed expectations have focused on inflation 
expectations of economists (e.g., Keane and Runkle [1990]). A few studies have examined the inflation expectations of consumers in general, using the aggregated Michigan data (Maddala, Fishe, and Lahiri [1981], Gramlich [1983], Batchelor [1986]). These studies mostly analyzed the Michigan question that allows only qualitative responses about the future path of inflation (up/down/no change). To use this question quantitatively the studies typically made strong assumptions to derive a continuous-valued expectations time-series from the aggregated data. Moreover, as already noted, because of aggregation bias the implications of these tests for individual rationality are not straightforward. One study, Batchelor and Jonung [1989], examined micro-level data on the inflation expectations of a small and short (one-year) Swedish panel, finding evidence of bias and inefficiency. However, rationality does not require that people's expectations be on target over the course of only a single year.

Flavin [1991], Dominitz [1993], and Alessie and Lusardi [1997] used micro-level data on income expectations to predict future income. While they did not formally test the rationality of these expectations, they did find a positive, if not very large, correlation between them and future realizations of income. Independently of this paper, Das and Von Soest [1996] tested the rationality of income expectations in a Dutch dataset. They found that income expectations were on average too low relative to subsequent realizations. However, their data is also limited to a relatively short panel (1984-88). As shown below, even five years might be too small to allow forecast errors to average out. Expectations might have been rational ex ante, but might not appear rational ex post. For instance the sample might by chance have received unexpectedly good income realizations over the period. ${ }^{1}$ This paper, by contrast, uses almost twenty years of micro-data, for many different kinds of expectations questions. Of course, even twenty years

\footnotetext{
${ }^{1}$ Das and Von Soest do not test whether income expectations help forecast behavior.
} 
might not be a long enough period. But such a result would be as significant as a finding of irrationality, because most micro studies are limited to datasets with a shorter sample period.

Even if expectations are not fully classical, people might still act on them and so they might help forecast spending. Of particular interest is whether sentiment surveys contain predictive information not available in other variables, most saliently current consumption. Two important recent studies have examined this issue using aggregate time series data, in an Eulerequation framework. $^{2}$ Carroll, Fuhrer, and Wilcox [1994] used the ICS and Acemoglu and Scott [1994] used a related Gallup poll in Britain. Both found significant excess sensitivity of consumption to sentiment, and suggested that sentiment might be picking up precautionary motives. But under this interpretation the sign of their estimated excess sensitivity is somewhat surprising: increased confidence led to a steeper consumption profile, i.e. to increased saving; whereas the simplest precautionary story would have increased confidence lead to less saving., Also, it remains an open question whether other variables might already incorporate the information in aggregate sentiment. While Carroll, Fuhrer, and Wilcox show that the ICS contains additional information beyond that available in aggregate income, other studies have found that financial variables, in particular stock prices, significantly reduce the contribution of aggregate sentiment in forecasting (Friend and Adams [1964], Ludvigson [1996]). By revisiting

\footnotetext{
2 The earliest study of which I am aware that used an Euler-equation framework to analyze sentiment is an unpublished Fed working paper by Burch and Gordon [1985], again using aggregate data. The Gulf War triggered a number of additional studies of aggregate sentiment, often by researchers in the Federal Reserve System (e.g., Throop [1992] and Carroll, Fuhrer, and Wilcox).

${ }^{3}$ A steeper consumption profile implies increased saving under the null hypothesis of the PIH. Outside the PIH this implication need not hold.

${ }^{4}$ Carroll, Fuhrer, and Wilcox note that frictions in consumption, e.g. due to habits, can explain the sign of their results. Acemoglu and Scott suggest a different explanation: higher confidence might be correlated with higher levels of income, which in turn might be correlated with a higher variance in income, and so a greater precautionary motive.
} 
the matter using micro data, this paper avoids potential aggregation bias and takes advantage of additional information in the cross-sectional distribution of sentiment.

Only a few papers have used micro-level expectations data in an Euler-equation framework. ${ }^{5}$ Two of the most interesting are by Flavin [1991] and Alessie and Lusardi [1997], who used income expectations as instruments for income in the related Euler equation for saving. Both rejected the PIH. However, both studies were limited to essentially single cross-sections (the 1967 SCF and a 1986 Dutch panel, respectively), making systematic heterogeneity in forecast errors a potential problem. ${ }^{6}$ To illustrate, Mariger and Shaw [1993] showed that in the Panel Study of Income Dynamics the excess sensitivity coefficient on lagged income growth varies in sign from year to year. For instance, the three-year sample used by Hall and Mishkin [1982] happens to yield a negative coefficient, but other short samples yield a positive coefficient. Mariger and Shaw conjectured that this instability might be due to aggregate shocks. But in contrast to this paper, without an independent measure of these shocks they were unable to test their conjecture directly.

\section{Data}

\section{A. The Survey of Consumer Attitudes and Behavior [CAB]}

The $\mathrm{CAB}$ is a nationally representative survey that since 1978 has been collected monthly. This paper uses the data from December 1978 through June 1996. In recent years

\footnotetext{
${ }^{5}$ Some of the earliest studies of sentiment, in the 1950's and 1960's, also used micro data. Their results were mixed. (See McNeil [1974] for a summary.) They generally had small sample sizes and short time horizons. Further, it is often hard to interpret their results because the models of consumption they used are generally different from current models.

${ }^{6}$ A recent paper by Jappelli and Pistaferri [1998] uses income expectations from an Italian Survey in an Euler equation. While they do not find excess sensitivity, they note this might be due to measurement error, especially in the timing of their expectational questions vis-à-vis the other variables. Also, they have only two cross-sections of expectations (1989 and 1991).
} 
about 500 households are sampled each month, in the earlier years two to three times as many were sampled. The five questions that comprise the widely followed ICS are as follows. The allowed responses are in brackets (underlining in original).

QFP $^{r}$. (Financial Position realization) We are interested in how people are getting along financially these days. Would you say that you (and your family living there) are better off or worse off financially than you were a year ago? [better now, same, worse now]

QFP $^{\mathrm{e}}$. (Financial Position expectation) Now looking ahead - do you think that a year from now you (and your family living there) will be better off financially or worse off, or just about the same as now? [will be better off, same, will be worse off]

QBC. (Business conditions) Now turning to business conditions in the country as a whole- do you think that during the next twelve months we'll have good times financially, or bad times, or what? [good times, good times with qualifications, pro-con, bad with qualifications, bad times]

QBC5. (Business conditions, 5 year horizon) Looking ahead, which would you say is more likely - that in the country as a whole we'll have continuous good times during the next 5 years or so, or that we will have periods of widespread unemployment or depression, or what? [good times, good times qualified, pro-con, bad times qualified, bad times]

QDurs. (Durables purchases) About the big things people buy for their homes-such as furniture \& refrigerator, stove, television, and things like that. Generally speaking, do you think now is a good or bad time for people to buy major household items? [good, pro-con, bad]

Some economists are wary of survey questions such as these. Instead of offering an exegesis, this paper will formally test the rationality of the responses and see whether they are correlated with behavior, specifically whether they help forecast spending. ${ }^{7,8}$ In a related paper, Souleles [1999b] shows that these same questions help predict household purchases of risky securities. Even controlling for past stock returns, households that are pessimistic about the

7 As for the particular wording of the questions, they have the virtue of having stayed the same over the sample period. Also, it is worth noting that most household-level data, not just sentiment, is based on households' selfreports.

${ }^{8}$ Carroll, Fuhrer, and Wilcox [1994] and others have shown that the aggregate ICS helps forecast aggregate consumption. Studies of the CAB inflation expectations, described below, have found that they are helpful in 
future buy fewer risky securities, ceteris paribus. ${ }^{9}$

A few additional notes are in order. First, questions QBC, QBC5, and QDurs ask the respondent about aggregate economic activity, while $\mathrm{QFP}^{\mathrm{r}}$ and $\mathrm{QFP}^{\mathrm{e}}$ ask about the household's own financial position. This suggests there might be more cross-sectional variation in $\mathrm{QFP}^{\mathrm{r}}$ and $\mathrm{QFP}^{\mathrm{e}}$ than in the other variables. Second, $\mathrm{QFP}^{\mathrm{e}}, \mathrm{QBC}$, and $\mathrm{QBC5}$ ask about the future ${ }^{10}$, whereas $\mathrm{QFP}^{\mathrm{r}}$ asks about the past year and QDurs asks about the present. Third, the wording of $\mathrm{QFP}^{\mathrm{e}}$ ("e" for expectation) matches that of $\mathrm{QFP}^{\mathrm{r}}$ ("r" for realization). Thus if someone is asked $\mathrm{QFP}^{\mathrm{e}}$ this year, and then $\mathrm{QFP}^{\mathrm{r}}$ next year, $\mathrm{QFP}^{\mathrm{e}}$ provides a forecast of what his answer to $\mathrm{QFP}^{\mathrm{r}}$ will be. However the response to $\mathrm{QFP}^{\mathrm{e}}$ is not the usual mathematical expectation because it is constrained to be one of three answers (better, worse, or the same), rather than assign a probability to each of the three possible outcomes. Because the answers to all five questions are discrete yet ordered, the estimation will include ordered probit specifications. For convenience, the better states ("better" or "good" or "good with qualification") are usually coded as +1 , the intermediate states ("same" or "pro-con") as 0, and the worse states ("worse" or "bad" or "bad with qualification") as $-1 .^{11}$

Figures 1 and 2 show the average response for each question month-by-month. All five variables are procyclical. Notably, the forward-looking $\mathrm{QFP}^{\mathrm{e}}$ appears to lead the backwardlooking $\mathrm{QFP}^{\mathrm{r}}$. For instance $\mathrm{QFP}^{\mathrm{e}}$ recovers more quickly from both the 1980-81 recession and

predicting CPI inflation, sometimes even better predictors than the inflation forecasts from professionals (Thomas [1999]).

9 A one-standard-deviation decline in $\mathrm{QFP}^{\mathrm{e}}$ led to about a $50 \%$ increase in the number of households selling securities and a $30 \%$ decrease in the number buying securities, albeit starting from small numbers of households buying and selling. These magnitudes are economically significant, and larger than the effects of a one-standarddeviation decline in past stock returns. For another application of the CAB, to tax cuts, see Shapiro and Slemrod [1995].

${ }^{10}$ These three questions make up the Expectations sub-index of the ICS, which in turn is a component of the Index of Leading Economic Indicators. 
the 1990 invasion of Kuwait. Nonetheless the two aggregate time series are highly correlated, at about 0.8 .

The $\mathrm{CAB}$ survey asks many additional questions. This paper will focus on the five questions above because they comprise the ICS, but will also consider the most salient of the additional questions, listed in the Appendix. There are two matching questions on business conditions related to QBC. Since one can be taken as the expectation of the other, they will be denoted $\mathrm{QBC}^{\mathrm{e}}$ and $\mathrm{QBC}^{\mathrm{r}}$. There are also matched questions about changes in prices, $\mathrm{QP}^{\mathrm{e}}$ and $\mathrm{QP}^{\mathrm{r}}$, and changes in the household's real income, $\mathrm{QY}{ }^{\mathrm{e}}$ and $\mathrm{QY}^{\mathrm{r}}$, over the following year and previous year respectively. $\mathrm{QU}^{\mathrm{e}}$ asks whether the respondent expects the national unemployment rate to increase or decrease over the next year. Even though there is no matching realization question about perceived unemployment over the past year, this question is used because precautionary saving might be sensitive to unemployment expectations. ${ }^{12}$ The answers to all these questions are again discrete and ordered. For business conditions QBC and household income QY, again +1 denotes the good state. But note that for inflation QP and unemployment QU, +1 denotes the bad state (an increase in inflation or unemployment). There are also matched pairs of continuous, quantitative questions about the inflation rate over the next and past 12 months (denoted by $\mathrm{Q} \Pi^{\mathrm{e}}$ and $\mathrm{Q} \Pi^{\mathrm{r}}$ ) and about the growth rate of the household's income $\left(\mathrm{QGY}^{\mathrm{e}}\right.$ and $\left.\mathrm{QGY}^{\mathrm{r}}\right)$. Unlike the five ICS questions $\mathrm{QFP}^{\mathrm{r}}$ to QDurs, not all of these additional questions were asked in every month of the sample period.

Even though the CAB surveys are archived as independent cross-sections, there is a short

\footnotetext{
${ }^{11}$ The ICS uses this coding in a diffusion index. For each question, the aggregate value at a given time is the number of people answering +1 at that time minus the number of people answering -1 . Such indexes omit the people answering 0 , as well as the distribution of the rest of the answers across people of different characteristics.

${ }^{12}$ Carroll [1992] was amongst the first to explicitly link QU to precautionary motives, in an aggregate time-series context. More recently Carroll et. al. [1996] examine the effects of cross-sectional differences in actual (ex post)
} 
panel aspect to them that has not previously been much exploited: Households are reinterviewed once and re-asked the same sentiment questions. Much effort was expended by the author to create a single, consistent panel dataset from the entire history of CAB cross-sections. Explicit forecast errors could then be calculated for the matched pairs of questions by taking a realization from the second interview (e.g., $\mathrm{QY}_{2}^{\mathrm{r}}$ ) and subtracting the corresponding expectation from the first interview $\left(\mathrm{QY}_{1}^{\mathrm{e}}\right)$. Thus, for a given household the error regarding income is defined as $\varepsilon \mathrm{Y}$ $\equiv \mathrm{QY}^{\mathrm{r}}{ }_{2}-\mathrm{QY}^{\mathrm{e}}{ }_{1}$. Errors for financial position, business conditions, and prices are defined similarly: $\varepsilon \mathrm{FP} \equiv \mathrm{QFP}_{2}^{\mathrm{r}}-\mathrm{QFP}_{1}^{\mathrm{e}}, \varepsilon \mathrm{BC} \equiv \mathrm{QBC}_{2}^{\mathrm{r}}-\mathrm{QBC}_{1}^{\mathrm{e}}$, and $\varepsilon \mathrm{P} \equiv \mathrm{QP}^{\mathrm{r}}{ }_{2}-\mathrm{QP}_{1}^{\mathrm{e}}$, respectively. Given the coding of the underlying variables $Q$ in $\{-1,0,1\}$, these errors $\varepsilon$ take on values in the set $\{-2,-1,0,1,2\}$. With a few exceptions, since December 1978 the second household interview in the $\mathrm{CAB}$ has taken place six months after the first interview. For consistency, for calculating forecast errors the sample is started in December 1978 and is limited to households reinterviewed after six months. Since the forecast horizon written into most of the expectational questions is one year, not six months, the timing in forming the errors $\varepsilon$ is unavoidably inexact. Nevertheless the timing is exogenous and unsystematic, since the sample covers every month over almost two decades. ${ }^{13}$ Extensions below will verify that this timing issue does not in fact drive the results.

For the quantitative questions on expected inflation and income growth, $\mathrm{Q} \Pi^{\mathrm{e}}$ and $\mathrm{QGY}$,

unemployment rates on balance sheets in the Survey of Consumer Finances. The results are consistent with precautionary saving.

${ }^{13}$ Suppose a household's first interview is in month $\mathrm{t}$, and $\mathrm{Q}_{1}^{\mathrm{e}}$ refers to the expected change in some variable $\mathrm{X}$ between months $t$ and $t+12$, and $Q_{2}^{r}$ from the second interview elicits the realized change $X_{t+6}-X_{t-6}$. Then the timing mismatch corresponds to the term $\left[\left(\mathrm{X}_{\mathrm{t}}-\mathrm{X}_{\mathrm{t}-6}\right)-\left(\mathrm{X}_{\mathrm{t}+12}-\mathrm{X}_{\mathrm{t}+6}\right)\right]$. This term can reasonably be assumed to average out over the long sample period, and in the cross-section. E.g., events that take place in months 7 to 12 after the first interview for one household, will appear in months 1 to 6 before the first interview for other households interviewed later, and hence tend to average out. 
continuous forecast errors can be computed analogously, e.g. $\varepsilon \mathrm{GY} \equiv \mathrm{QGY}_{2}^{\mathrm{r}}-\mathrm{QGY}^{\mathrm{e}}{ }_{1} \cdot{ }^{14}$ For inflation there is more flexibility in computing the errors since the actual consumer inflation rate can be measured independently via the CPI. Therefore three different forecast errors $\varepsilon \Pi$ are computed. The "subjective" error $\varepsilon \Pi^{\text {subj }} \equiv \mathrm{Q} \Pi_{2}^{\mathrm{r}}-\mathrm{Q} \Pi_{1}^{\mathrm{e}}$ compares the inflation rate the respondent expects over the next 12 months, taken from the first interview, with the inflation rate the respondent believes was realized over the past 12 months, taken from the second interview six months later. Again, because the realization variable is not elicited twelve months later the timing is not exact. To avoid this problem, the "objective" error $\varepsilon \Pi^{\mathrm{obj}} \equiv \Pi^{\mathrm{r}}{ }_{12}-\mathrm{Q} \Pi^{\mathrm{e}}{ }_{1}$ compares the 12-month inflation rate the respondent expected in the first interview with the actual inflation rate over the next 12 months, according to the $\mathrm{CPI}\left(\Pi^{\mathrm{r}}{ }_{12}\right)$. In this case the timing is exact. The third error $\varepsilon \Pi_{6}{ }^{\mathrm{obj}} \equiv \Pi^{\mathrm{r}}{ }_{6}-\mathrm{Q} \Pi^{\mathrm{e}}{ }_{1}$ uses for its realization the CPI inflation rate over only the first six months following the first interview (though annualized). This error can be contrasted with $\varepsilon \Pi^{\mathrm{obj}}$ to investigate the effects of the six-month mistiming in the other forecast errors.

The CAB also includes a number of demographic questions. Since some of these changed across surveys, great care was taken to create a set of demographic variables consistent across the entire sample (and consistent with the CEX). The Appendix provides more details. The main sample exclusion concerns the survey respondent. The sample drops an observation when there is a married couple in the household but the respondent is neither the husband nor spouse. (Most such respondents appear to be older children of the couple.) This should help

\footnotetext{
${ }^{14}$ There is an additional complication regarding the timing of $\mathrm{QGY}^{\mathrm{e}}$. The corresponding realization question elicits the level of household income (not the growth rate) in the previous calendar year. Since the second interview follows after only six months, to compute a non-zero growth rate for income from one year to the next, $\mathrm{QGY}^{\mathrm{r}}$, the sample for this question must be limited to households whose first interview takes place in the second half of the year, so that the second interview takes place in the following calendar year. By contrast, the expectational question $\mathrm{QGY}_{1}^{\mathrm{e}}$ asked in the first interview refers to income growth over the next twelve months, so its reference period will somewhat lag the reference period of the computed QGY.
} 
make the respondent's answers more representative of the entire household. Demographic variables referring to the reference person were switched to refer to the head of household (i.e., for a married couple, the male, following the convention in the literature). An additional exclusion was adopted in forming the subjective forecast errors (i.e., all but the objective inflation errors): to make the answers in both interviews more comparable, the same person had to be the respondent in both interviews.

\section{B. The Consumer Expenditure Survey [CEX]}

Because the $\mathrm{CAB}$ survey does not include much data on expenditures, it is matched with the Consumer Expenditure Surveys, from 1982-1993. ${ }^{15}$ CEX households are interviewed four times, three months apart (though starting in different months for different households). The reference periods for expenditure cover the three months before each interview. Strictly speaking the Euler equation used below applies only to nondurable consumption, but for gauging the aggregate effect of sentiment total consumption also matters. Indeed, some analysts have suggested that sentiment matters most for durables purchases. Therefore, for each householdquarter, both real nondurable expenditure and real total expenditure were computed (1982-84\$).

The CEX sample was selected in standard ways to improve the measurement of consumption. A household was dropped from the sample if there were multiple "consumer units" in the household, or the household lived in student housing or the head of household was a farmer. A household-quarter was dropped if no food-expenditure was recorded in the quarter, or any food was received as pay in the quarter. The Appendix provides further details about the data. 


\section{Econometric Specifications}

The sentiment of the CEX households will be imputed from the sentiment of demographically similar households in the CAB. Since both surveys ran monthly over the 1980's and 1990's and contain a rich, overlapping set of demographic variables, the imputation can be made very fine. Table 1 shows the means of the main variables used. The CAB sample is somewhat more highly educated and likely to live in the South. But generally the means are rather similar, as one would expect from two representative datasets. The imputation proceeds in two steps.

The first step takes place in the CAB. For the discrete sentiment variables, since their responses are ordered, both linear and ordered probit models will be estimated. In the latter, for a given sentiment variable $\mathrm{Q} \in\{-1,0,+1\}$ and household $\mathrm{i}$, let $\mathrm{Q}_{\mathrm{i}, \mathrm{t}}{ }^{*}$ be the corresponding (continuous) latent index at time $t$, representing i's underlying sentiment or confidence. $\mathrm{Q}_{\mathrm{i}, \mathrm{t}}{ }^{*}$ is assumed to take the following form:

$$
\mathrm{Q}_{\mathrm{i}, \mathrm{t}}{ }^{*}=\mathbf{a}_{\mathbf{0}}{ }^{\prime} \mathbf{t i m e}_{\mathbf{t}}+\mathbf{a}_{\mathbf{1}}{ }^{\prime} \mathbf{Z}_{\mathbf{i t}}+\mathrm{u}_{\mathrm{i}, \mathrm{t} \cdot}
$$

Except for the questions on inflation and unemployment, larger values of $\mathrm{Q}^{*}$ reflect better states. $\mathbf{Z}$ is the vector of demographic instruments used to link the two datasets, from Table 1. time includes a full set of month dummies (a different dummy for each month of each year). These dummies will allow for changes in the average level of sentiment from month to month. Since the cross-sectional distribution of sentiment around the average can also change over time, some of the demographic variables are interacted with the month dummies. Because there are well over 100 months in the sample, to keep the computational requirements tolerable only a few variables could be interacted simultaneously. Preliminary analysis found that for most sentiment

\footnotetext{
15 The first wave of the CEX, 1980-81, is not used because its data are generally poorer than the data from the
} 
questions the effects of age and income varied the most significantly over time, so $\mathbf{Z}$ also includes month-interactions for these two variables. Ordered logits were also estimated, but since the results were quite similar they are not reported. For the continuous variables QGY and QП, the same functional form in (1) is estimated by OLS.

The second step takes place in the CEX. The estimated coefficients from the first step, $\hat{\mathbf{a}}_{\mathbf{0}}$ and $\hat{\mathbf{a}}_{1}$, are used to impute the (continuous index value) level of sentiment $\hat{Q}$ of the CEX households with the same demographic characteristics $\mathbf{Z}$ :

$$
\hat{Q}_{\mathrm{i}, \mathrm{t}}=\hat{\mathbf{a}}_{\mathbf{0}}{ }^{\prime} \mathbf{t i m e}_{\mathbf{t}}+\hat{\mathbf{a}}_{\mathbf{1}} \mathbf{Z}_{\mathbf{i t}} .
$$

Lagged $\hat{Q}$ is then added to a standard linearized Euler equation for consumption. For household $i$ the change in $\log$ consumption between periods $t+1$ and $t$ is specified as

$$
\mathrm{dlnC}_{\mathrm{i}, \mathrm{t+1}}=\mathbf{b}_{\mathbf{0}}{ }^{\prime} \mathbf{t i m e}_{\mathbf{t}}+\mathbf{b}_{\mathbf{1}} \mathbf{W}_{\mathrm{i}, \mathrm{t+1}}+\mathrm{b}_{2} \hat{Q}_{\mathrm{i}, \mathrm{t}}+\eta_{\mathrm{i}, \mathrm{t}+1} .
$$

Following Zeldes [1989], Dynan [1993], Lusardi [1996], and Souleles [1999], W will include the age of the household head and changes in the number of adults and in the number of children. These variables help control for the most basic changes in household preferences over time. ${ }^{16}$

For a given household the consumption changes in equation (3) are taken over successive three-month periods. To keep the sentiment data timely, the time-varying components of $\hat{Q}_{\mathrm{i}, \mathrm{t}}$ are estimated from the $\mathrm{CAB}$ survey corresponding to the first of the three months covered by $\mathrm{C}_{\mathrm{i}, \mathrm{t}}$. For instance, consider the case in which $\mathrm{C}_{\mathrm{i}, \mathrm{t}}$ records consumption in November 1990 to January 1991 (and $\mathrm{C}_{\mathrm{i}, \mathrm{t}+1}$ covers February-April 1991). In equations (1) and (2), the month dummies time $\mathrm{t}_{\mathrm{t}}$

\footnotetext{
following waves.

${ }^{16}$ As Deaton [1992] notes, by restricting the variables in $\mathbf{Z}$ or expanding the variables in $\mathbf{W}$, it would be possible to eliminate most any excess sensitivity. Therefore $\mathbf{W}$ is restricted to this commonly used set of controls (age and changes in family size), for comparison with previous studies and to retain power to test for excess sensitivity and for systematic heterogeneity in forecast errors. See also the survey of specifications in Table 5.1 of Browning and Lusardi [1996].
} 
and the month-interacted variables in $\mathbf{Z}_{\mathbf{i t}}$ would then correspond to the November $1990 \mathrm{CAB}$. $\hat{Q}_{\mathrm{i}, \mathrm{t}}$ is therefore predetermined in equation (3), and so under the PIH the coefficient $\mathrm{b}_{2}$ should be zero. That is, given current consumption, current sentiment should not help predict future consumption.

OLS estimation of equation (3) would neglect the fact that $\hat{Q}$ is a generated regressor. To take this into account the two-sample instrumental-variables technique of Angrist and Krueger [1992] will be used, although here the technique is not required for consistency but only to adjust the standard errors for the additional variation arising from the first estimation step. This technique requires that both estimation steps be linear, so for the reported excess sensitivity tests equation (1) is estimated by OLS even for the discrete sentiment questions. A previous version of this paper reported instead the ordered probit results for the discrete questions. Comparing the results shows that imposing linearity makes very little difference to the excess sensitivity tests; the signs and significance of the coefficients in equation (3) are quite similar. ${ }^{17}$ The standard errors in (3) are also corrected for general heteroscedasticity and serial correlation by household.

The month dummies in equation (3) control for all aggregate (uniform) effects, including seasonality, aggregate interest rates, and any other macro variables like stock prices that might incorporate some of the same information available in the aggregate time series of sentiment. Since the same dummies are used in the first step in equation (1), in (3) they effectively partial

\footnotetext{
${ }^{17}$ Jappelli, Pischke, and Souleles [1999] also applied this two-sample estimator to excess sensitivity tests. They too imposed linearity on a first-step specification that was originally discrete, and found that the final excess sensitivity results were not sensitive to this imposition. Alternatively, equations (1) and (3) can be jointly bootstrapped, estimating equation (1) by ordered probit. However each ordered probit takes many hours, making bootstrapping infeasible for the full set of results below. The bootstrap standard errors were however computed for the first specification in Table 3 (for $\mathrm{QFP}^{\mathrm{r}}$ for nondurable consumption). The resulting significance levels for the coefficients in equation (3) were similar to those reported using the two-sample estimator.
} 
out the monthly average level of sentiment, leaving only cross-sectional variation in $\hat{Q}$. Although using these time dummies makes it harder to find a significant effect of sentiment in predicting consumption, they provide a crisp test of whether the micro data contains useful information not available in the aggregated data.

This paper also tests the rationality of people's forecasts, namely their unbiasedness and efficiency. The results can also be interpreted as characterizing the shocks that have ex post hit different types of households. Efficiency requires that forecast errors be uncorrelated with any variable in an agent's information set at the time of forecast; otherwise the forecast does not take advantage of all available information. Time-series analyses of the efficiency of inflation expectations often test for serial correlation in inflation forecast errors. However, for each sentiment question the $\mathrm{CAB}$ contains only one forecast error per household, so it is impossible to test for serial correlation at the micro level. ${ }^{18}$ This paper instead tests efficiency by looking for systematic demographic components in households' forecast errors. The focus is on crosssectional heterogeneity, because that is the variation available in the $\mathrm{CAB}$ data, and the variation exploited in most excess sensitivity tests in micro data.

Specifically, efficiency will be tested using a specification similar to equation (1), but with the forecast errors $\varepsilon$ (defined above) as the dependent variable:

$$
\varepsilon_{\mathrm{i}, \mathrm{t}+1}{ }^{*}=\mathbf{d}_{\mathbf{0}}{ }^{\prime} \mathbf{t i m e}_{\mathbf{t}}+\mathbf{d}_{\mathbf{1}}{ }^{\prime} \mathbf{Z}_{\mathbf{i t}}+\mathrm{V}_{\mathrm{i}, \mathrm{t}+1}
$$

where $t$ refers to the first household interview in the $C A B, t+1$ to the second interview. For instance, for income the error is $\varepsilon \mathrm{Y}_{\mathrm{i}, \mathrm{t}+1} \equiv \mathrm{QY}_{\mathrm{i}, \mathrm{t}+1}^{\mathrm{r}}-\mathrm{QY}_{\mathrm{it} .}^{\mathrm{e}}{ }^{19}$ Since the demographic variables $\mathbf{Z}_{\mathrm{it}}$

\footnotetext{
${ }^{18}$ One could test for serial correlation in the aggregated sample data, but as already explained that could lead to aggregation bias. Since individual agents needn't know the forecast errors of all other agents, the lagged aggregate forecast error isn't necessarily in the information set of any single agent.

19 Despite the complications that the six-month mistiming in forming the forecast errors poses for testing the rationality of forecast errors, the timing has an advantage for the Euler equation tests: The errors $\varepsilon_{t+1}$ cover the same
} 
are known to agent $i$ at the time $t$ of forecast, efficiency requires that $\mathbf{d}_{\mathbf{1}}=0$. The time dummies control for cross-sectional correlation due to (perfectly uniform) aggregate shocks, which Keane and Runkle [1990] emphasize. When $\varepsilon$ is restricted to $\{-2,-1,0,1,2\}$ the estimation is by ordered probit, but for the continuous variables $\varepsilon G Y$ and $\varepsilon \Pi$ OLS is used.

Returning to Euler equation (3), the residual $\eta$ can potentially include many factors, such as measurement error, approximation error from linearizing the Euler equation (e.g., Ludvigson and Paxson [1997]), or unobserved heterogeneity in discount rates. Other studies have already analyzed the complications such factors pose in estimating Euler equations, including the possibility of spurious excess sensitivity. (For a review, see Deaton [1992] or Browning and Lusardi [1996].) The focus here is instead on a different component of $\eta$ : the innovation in consumption resulting from forecast errors (shocks) regarding household income, financial position, and the other sentiment variables. Systematic heterogeneity in forecast errors has not received much empirical scrutiny, even though it can lead to spurious inference in Euler equations and more generally in any forward-looking model. In (3), for consistent estimates of $b_{2}$ the forecast errors need to be uncorrelated with the excess sensitivity regressor $\hat{Q}$. Most studies rely on the time dummies to soak up all systematic components of forecast errors, such as shocks due to the business cycle. But this makes the strong assumption that such shocks hit all people uniformly.

The problem can be illustrated with a simple example. Suppose there are two kinds of households in the population, those with high education and those with low education. Suppose further that in addition to idiosyncratic shocks there are group-level shocks that hit all members

six-month period as $\mathrm{d} l n_{\mathrm{t}+1}$. Therefore $\varepsilon_{\mathrm{t}+1}$ will appropriately incorporate any news that comes out over the six months. (The fact that the reference period for the realization $\mathrm{Q}_{\mathrm{t}+1}^{\mathrm{r}}$ extends six months further back in time than the reference period for $\mathrm{C}_{\mathrm{t}}$ is irrelevant. These first six months are already in the agents' information sets at $t$.) 
within an education group the same way, but hit each group differently. In this case time dummies will capture any common effects across the two groups, but will not control for the group-level shocks. Thus, even if each household is behaving according to the $\mathrm{PIH}$, a regression of household consumption growth on time dummies and household education status would produce a significant coefficient for education. If the regression does not control for education but includes an excess sensitivity regressor correlated with education, this regressor will be found to be significant even if the PIH is true, resulting in spurious excess sensitivity. More generally, if forecast errors are correlated with household demographics, they are likely to be correlated with most regressors of interest in forward-looking models.

Unlike previous studies, with direct measures of forecast errors this paper is uniquely able to test the implications of systematic heterogeneity in the errors. Shocks to variables like household income and financial position, as well as in aggregate business conditions and inflation, must be among the most important sources of the overall innovation in consumption in $\eta .^{20,21}$ If in equation (4) $\mathbf{d}_{\mathbf{1}} \neq 0$, the errors $\varepsilon$ are not uniform across households, and then any excess sensitivity estimated in (3) might be spurious. The aggregate time dummies in (3) would not control for such heterogeneity. To assess this possibility, the forecast errors $\hat{\varepsilon}$ of the CEX households will be imputed from the errors of the CAB households with the same demographic characteristics $\mathbf{Z}$, in another two-step process. Then the term $\mathrm{b}_{3} \hat{\varepsilon}_{\mathrm{i}, \mathrm{t}+1}$ will be added to equation

${ }^{20}$ Indeed shocks to overall financial position $\varepsilon F P$ might be more representative of innovations to household consumption and welfare than shocks to just current income, which are more commonly analyzed.

21 Even if the residual $\eta$ in (3) contains more than the forecast errors $\varepsilon$ for income, financial position, etc., orthogonality of $\varepsilon$ is a necessary condition for orthogonality of $\eta$. E.g., if people's forecasts of future income are inefficient, correlated with their demographics, then so will be their innovation in consumption. Of course other factors in $\eta$ can also generate excess sensitivity, but under the null hypothesis that forecast errors are classical these factors will be independent of $\varepsilon$. Thus other factors alone cannot explain the effects of controlling for $\varepsilon$ in equation (3). In any case, even if these other factors are present, heterogeneity in forecast errors also needs to be investigated. Similarly, people might use more information to forecast than just the demographic variables in $\mathbf{Z}_{\mathrm{it}}$, but since $\mathbf{Z}_{\mathrm{it}}$ is part of their information set, efficiency with respect to $\mathbf{Z}_{\mathrm{it}}$ is a necessary condition. 
(3). Under the alternative hypothesis that excess sensitivity is being generated by the demographic components in forecast errors, one would expect to find $b_{2}=0$ and $b_{3}>0 \quad\left(b_{3}<0\right.$ for inflation and unemployment), since the PIH allows consumption to respond to the innovations represented by $\hat{\varepsilon} \cdot{ }^{22}$

The errors $\hat{\varepsilon}$ can be imputed in two different ways. First, equation (4) can be estimated directly on the forecast errors $\varepsilon_{\mathrm{t}+1} \equiv \mathrm{Q}_{\mathrm{t}+1}^{\mathrm{r}}-\mathrm{Q}_{\mathrm{t}}^{\mathrm{e}}$ in the $\mathrm{CAB}$ and then used to impute $\hat{\varepsilon}_{\mathrm{t}+1}=$ $\overbrace{Q^{r}{ }_{t+1}-Q^{e}}{ }_{t}$ in the CEX. Here again the first household interview $\mathrm{t}$ in the CAB is chosen to correspond to $\mathrm{C}_{\mathrm{it}}$ in the CEX. Alternatively, in an extension equation (1) is first used to impute the levels of sentiment in the CEX, both realized $\hat{Q}^{\mathrm{r}}{ }^{\mathrm{r}+1}$ and expected $\hat{Q}_{\mathrm{t}}^{\mathrm{e}}$. The difference between these variables then gives the forecast errors $\hat{\varepsilon}_{\mathrm{t}+1}=\hat{Q}^{\mathrm{r}+1}-\hat{Q}_{\mathrm{t}}^{\mathrm{e}}$, with the timing matching the quarterly consumption change in equation (3).

\section{Results: Forecast Errors and the Rationality of Expectations}

This section analyzes households' forecast errors, in particular testing whether expectations are unbiased and efficient. As a preliminary step the working-paper version of this paper presented $3 \times 3$ cross-tabulations of the matched pairs of discrete $C A B$ variables, the expectational variables $\mathrm{Q}_{1}^{\mathrm{e}}$ with their corresponding realizations $\mathrm{Q}_{2}^{\mathrm{r}}$, both coded in $\{-1,0,1\}$.

\footnotetext{
${ }^{22}$ For instance, Deaton [1992] discusses a model in which income innovations are generated according to $\Delta \mathrm{y}_{\mathrm{it}}=\mathrm{e}_{\mathrm{t}}+$ $\mathrm{g}_{\mathrm{i}} \mathrm{e}_{\mathrm{t}}+\mathrm{w}_{\mathrm{it}}-\mathrm{w}_{\mathrm{i}, \mathrm{t}-\mathrm{l}}$, where $\mathrm{e}_{\mathrm{t}}$ is a common permanent shock, $\mathrm{w}_{\mathrm{it}}$ is an idiosyncratic transitory shock, and $\mathrm{g}_{\mathrm{i}}$ is a meanzero loading factor capturing the non-uniform effect of the aggregate shock across different households. Under the $\mathrm{PIH}$, then $\Delta \mathrm{c}_{i t}=\mathrm{e}_{\mathrm{t}}+\mathrm{g}_{\mathrm{i}} \mathrm{e}_{\mathrm{t}}+\mathrm{w}_{\mathrm{it}} \mathrm{r} /(1+\mathrm{r})$, for interest rate $\mathrm{r}$. Hence innovations to household income feed directly into consumption, according to their persistence and cross-sectional loadings, generating $b_{3}>0$. Equation (4) can be thought of as the empirical generalization of this model for income innovations $\Delta y$. Analogously one would expect positive innovations to household financial position and aggregate business conditions to lead on average to increases in consumption, generating $b_{3}>0$ for these variables as well. Note that in this model for $\Delta c$, time dummies will control for only the first term, the common shock $e_{t}$. If the other two terms are correlated with the excess
} 
Comparing $\mathrm{QP}^{\mathrm{r}}{ }_{2}$ and $\mathrm{QP}^{\mathrm{e}}{ }_{1}$ reveals that inflation more often turned out higher than expected, than lower than expected, over the sample period. Similarly, business conditions $\left(\mathrm{QBC}_{2}^{\mathrm{r}}\right)$ more often turned out worse than expected (relative to $\mathrm{QBC}^{\mathrm{e}}{ }_{1}$ ). Thus, for both $\mathrm{QBC}$ and $\mathrm{QP}$, "bad" surprises were more common than "good" surprises. To test unbiasedness formally one needs to specify how much worse it is to end up two places (cells) off the diagonal in the $3 \times 3$ cross-tabs than one place off. However, one can avoid taking a stand on this tradeoff by collapsing the $3 \times 3$ tables into $2 \times 2$ tables, by either dropping the middle ( 0 's) responses or by merging them into one of the other two responses $(+1$ or -1$){ }^{23}$ Nonparametric sign tests can then be used to test for bias, namely whether the probability of falling into the single northeast cell significantly differs from the probability of falling into the single southwest cell. Whichever way one handles the middle responses, these tests (not reported) reject unbiasedness for all four matched pairs of discrete sentiment questions. However, dropping or merging the middle responses wastes a good deal of information.

Alternatively one can explicitly parametrize the errors, most simply by treating their values in $\{-2,-1,0,1,2\}$ as cardinal; i.e., by assuming that being two places off the diagonal is twice as bad as being one place off. Then one can estimate the mean population forecast error $\mu$ by regressing the errors $\varepsilon$ on a constant by OLS. The reported standard errors are corrected for the fact that the errors across households in a given month can be correlated by common shocks. In Figure 3, the resulting estimates of $\mu$ for $\varepsilon F P, \varepsilon B C$, and $\varepsilon Y$ are all significantly negative, while the average inflation error $\varepsilon \mathrm{P}$ is positive. (Recall that for inflation, +1 represents the bad state,

sensitivity regressor Q, as is likely if forecast errors are inefficient, then this would generate spurious excess sensitivity even conditional on the time dummies.

${ }^{23}$ E.g., one could test the rationality of binary variables such as "a) Will conditions improve or at least stay the same, or b) will conditions worsen?" This variable would correspond to grouping the 0 's with the +1 's. 
the reverse of the other variables.) Hence the forecast errors are biased, at least ex post. ${ }^{24}$ Consistent with the non-parametric tests above, bad shocks predominated in the sample.

Even though realizations were on average worse than expected, one should not conclude from these results that people are generally over-optimistic or over-confident, uniformly across time. One can test for time effects in the forecast errors $\varepsilon$, even without cardinalizing them, by using ordered probits. Equation (4) was first estimated using only the time dummies as regressors. The resulting coefficients and standard errors are graphed in Figure 3. For clarity year dummies are presented, but the conclusions are the same using the full set of month dummies. For all four discrete forecast errors the chi-squared tests indicate that the year dummies are jointly very significant. That is, there is significant variation in households' forecast errors from year to year. More striking is their pattern over time. The "non-price" errors $\varepsilon \mathrm{FP}, \varepsilon \mathrm{BC}$, and $\varepsilon \mathrm{Y}$ are very negative throughout the early 1980's and the early 1990's. It appears that people were surprised by the recessions, repeatedly over their duration. ${ }^{25,26}$ However, recalling the procyclicality of sentiment in Figures 1 and 2 (in particular the fact that $\mathrm{QFP}^{\mathrm{e}}$

${ }^{24}$ While the reported standard errors control for cross-sectional correlation from common shocks, they do not reflect the fact that the forecast horizons for households interviewed in successive months partially overlap, potentially generating serial correlation in the residuals. Since the forecast periods cover six months, this correlation could extend up to 5 months. (For $\mathrm{e}^{\mathrm{obj}}$, with a forecast horizon of one year, there is 11 months of overlap.) To control for this, the regressions were rerun limiting the sample to non-overlapping forecast periods (e.g., in one regression using only $\mathrm{CAB}$ interviews in January and July, in another regression using only February and August, etc.). Even though this throws away $5 / 6$ of the data, for $\varepsilon F P$ and $\varepsilon \mathrm{Y}$ the average $\mu$ remained significantly negative for all samples considered (i.e., for all six pairs of months). For $\varepsilon \mathrm{BC}$ and $\varepsilon \mathrm{P}$ the means remained negative and positive respectively, and were significant in about half the non-overlapping samples.

25 Under basic models of rational expectations, efficiency requires that individual agents' forecast errors be independent across time. Even though only one forecast error is available per household, one can test for serial correlation in the aggregated forecast errors, i.e. in the estimated month dummies underlying the figures. For Figure 3 , there is significant autocorrelation through $12,20,4$, and 21 months for $\varepsilon \mathrm{FP}, \varepsilon \mathrm{BC}, \varepsilon \mathrm{Y}$, and $\varepsilon \mathrm{P}$, respectively. For Figure 4 below, autocorrelation is significant through 4, 22, 21, and 11 months for $\varepsilon \mathrm{GY}, \varepsilon \Pi^{\mathrm{subj}}, \varepsilon \Pi^{\mathrm{obj}}$, and $\varepsilon \Pi_{6}{ }^{\mathrm{obj}}$, respectively. However, recall that tests of efficiency on aggregated data are subject to aggregation bias.

${ }^{26}$ The overlapping forecast periods described above could generate some autocorrelation through 5 months. But Figure 3 and the results in the previous note show that the autocorrelation in the time effects lasts much longer than this. The diagrams and conclusions remain qualitatively the same on limiting the sample to non-overlapping periods 
appears to be leading), one should not conclude that people altogether fail to foresee the business cycle. Rather, it appears that people understate the amplitude or duration of the cycle, in both downturns and upturns. Nonetheless, the pseudo $\mathrm{R}^{2}$ s suggest that time effects explain only a small part of the variation in the forecast errors. The time effects are more significant and produce a larger $\mathrm{R}^{2}$ for the forecast error for aggregate activity, $\varepsilon \mathrm{BC}$, than for the householdspecific errors $\varepsilon F P$ and $\varepsilon Y$.

Figure 3d) records the results for the discrete inflation forecast errors $\varepsilon \mathrm{P}$. The year effects swing from positive to negative. Evidently inflation was higher than expected at the end of the 1970's, but then people were surprised by how quickly it abated in the early to mid $1980{ }^{\prime} .^{27}$ Figure 4b) presents analogous results for the continuous, subjective inflation error, $\varepsilon \Pi^{\text {subj }}$. It too dramatically declines from positive to negative in the early 1980 's, and is positive on average over the sample. Figure $4 c$ ) shows the objective forecast error $\varepsilon \Pi^{\mathrm{obj}}$, which uses as its realization the actual CPI inflation rate $\Pi_{12}$ over the next 12 months (as opposed to the CAB

as above, or on using the full set of month dummies in equation (4). Estimating (4) by OLS produces year effects that are similar in pattern and even magnitude to those in Figure 3.

27 There is a small discrepancy in the wording of $\mathrm{QP}^{\mathrm{e}}$ and $\mathrm{QP}^{\mathrm{r}}$. $\mathrm{QP}^{\mathrm{e}}$ asks about prices in general, whereas $\mathrm{QP}^{\mathrm{r}}$ asks about the prices of goods the household itself buys. This distinction should not matter much here. First, the CAB data are representative, so the prices of goods bought should be relatively close to the consumer price level. Second, any discrepancy is extremely unlikely to explain the dramatic shift in forecast errors from positive to negative during the disinflation in the early 1980's (Figure 3d)). Third, the continuous questions $\mathrm{Q} \Pi^{\mathrm{e}}$ are about aggregate prices and so Figure 4c) is not subject to the discrepancy, yet yields the same pattern. Fourth, Croushore [1998] documents a very similar pattern using the aggregate time series for inflation expectations from the Livingston survey and the Survey of Professional Forecasters, where again there is no discrepancy in the wording of the survey questions. Fifth, the results are both qualitatively and quantitatively very similar on using the regional CPI for the census region in which the household lives, instead of the national CPI. Sixth, even though $\mathrm{QP}^{\mathrm{e}}$ doesn't specifically mention the CPI, both the results of the previous literature and the staff at the Institute for Social Research suggest that the CPI is the appropriate benchmark. The ISR surveyors prod respondents for the prices of "the things people buy," but deliberately avoid using jargon like "CPI-U". Seventh, the conclusions are qualitatively very similar using instead the PCE and GDP deflators for the realizations $\Pi$. In fact, the bias in Figure 4c) becomes even worse, the estimated $\mu$ more negative, because the deflators didn't rise as much as the CPI during the oil shocks at the beginning of the sample period. 
variable $Q \Pi^{\mathrm{r}}$ used in Figure 4b), which is not available after 1985). ${ }^{28}$ The errors again decline with the disinflation in the early 1980 's. The magnitude of this decline is both statistically and economically significant, with inflation starting about two percentage points higher than expected in 1979 but falling 2.5 percentage points lower than expected by 1982, a 4.5 percentage point change. More recently, throughout the 1990's households were repeatedly surprised by the low levels of inflation, by about 1 to 2 percentage points. Such negative errors dominate in the longer sample, making the overall average error $\mu$ significantly negative for $\varepsilon \Pi^{\mathrm{obj}}$, whereas it was positive for $\varepsilon \Pi^{\text {subj }}$ over the shorter sample period. These results vividly illustrate how sensitive estimates of bias can be to the sample period, even for long samples. Figure 4d) shows the objective forecast errors $\varepsilon \prod_{6}{ }^{\text {obj }}$ using instead the CPI inflation rate over only the first six months after households' first interviews (annualized), to see the effects of the six-month mismatch between expectations and realizations in the other variables. Reassuringly, the results do not much differ from Figure 4c), suggesting that the mismatch is not driving the results. ${ }^{29}$ More generally, the results for inflation are robust across different definitions of inflation and its forecast error.

Figure 4a) displays the forecast errors $\varepsilon \mathrm{GY}$ for income growth, which are available only in the later part of the sample period. Despite the larger standard errors (reflecting the smaller sample size), the forecast errors still significantly vary over time. They start declining in 1990,

\footnotetext{
${ }^{28}$ The drawbacks to using actual inflation emphasized by Keane and Runkle [1990] do not apply here. First, unlike the GDP deflator the CPI is not revised. (The seasonal adjustment can be changed, but this is unlikely to be important. To avoid any problem the reported results use the non-seasonally-adjusted CPI. Using the seasonally adjusted CPI instead made extremely little difference.) Second, revisions are a problem only if the revised variable is used as a regressor to test efficiency but was not in agents' information sets. The efficiency tests here do not use revised variables as regressors.

${ }^{29}$ In addition to having similar time-series properties, the cross-sectional properties of $\varepsilon \Pi_{6}{ }^{\text {obj }}$ are similar to those for $\varepsilon \Pi^{\mathrm{obj}}$ in Table 2 below, both qualitatively and quantitatively. Further, their six-month difference does not materially change the Euler equation results for $\varepsilon \Pi^{\mathrm{obj}}$ below in Table 4. As for the other forecast errors, there is no reason to
} 
and rebound only after 1993, when income growth was 2.5 percentage points lower than expected. Again, people seem to have been surprised by the recession, and perhaps also by the weakness of the subsequent recovery. ${ }^{30,31}$

As a further check that the six-month timing mismatch is not driving the results, forecast errors with the correct timing can be estimated for each household i. For each matched expectational question $\mathrm{Q}_{\mathrm{i}}^{\mathrm{e}}$, the realization 12 months later $\hat{Q}^{\mathrm{r}}{ }_{12, \mathrm{i}}$ can be estimated from the corresponding realizations $Q_{j}^{r}$ of other households $j$ with the same characteristics $\mathbf{Z}$ that are interviewed 12 months later. The resulting forecast errors $\varepsilon_{12} \equiv \hat{Q}^{\mathrm{r}}{ }_{12}-\mathrm{Q}_{1}^{\mathrm{e}}$ exhibit very similar means and time effects as those graphed in Figures 3 and $4 a-b)$. The other conclusions below also persist, confirming that the timing mismatch is not a problem. ${ }^{32,33}$

In sum, consumer forecasts appear to be biased. However, it is very difficult to distinguish whether they are biased ex ante, or just ex post, requiring many years -- even decades -- to meet their targets on average. In either case the bias is problematic for empirical studies

believe that they would be any more sensitive to the six-month mistiming. Their Euler equation results do not qualitatively change on slightly perturbing the timing of the mapping between the CEX and CAB samples.

${ }^{30}$ Though part of the reason $\varepsilon$ GY troughs only in 1993 might be the lag in its reference period, discussed above.

31 Again, these conclusions persist on dropping the overlapping forecast periods. The average errors $\mu$ for $\varepsilon \Pi^{\text {subj }}$ and $\varepsilon \Pi_{6}{ }^{\text {obj }}$ remain significant in all six non-overlapping samples. (For $\varepsilon \Pi^{\text {obj }} \mu$ is less significant, but with a 12 month horizon, twice as much of the data $(11 / 12)$ had to be dropped. Even so $\varepsilon \Pi^{\text {obj }}$ still varies significantly over time, in all the non-overlapping samples.) For $\varepsilon \mathrm{GY} \mu$ remains significant in over half the non-overlapping samples. To allow for one month's delay in the release of the CPI, this analysis was redone dropping 6/7 of the data for $\varepsilon \Pi_{6}{ }^{\text {obj }}$ and $12 / 13$ for $\varepsilon \Pi^{\mathrm{obj}}$. The conclusions are the same. As already noted, the serial correlation in the aggregated inflation errors lasts well over a year.

32 Because $\varepsilon_{12}$ is continuous, the estimation is by OLS. While this changes the magnitude of the time effects compared to the ordered probit time effects for $\varepsilon$ graphed in Figure 3, the differences are small even quantitatively. Overall, the differences in the time effects for $\varepsilon_{12}$ versus $\varepsilon$ are generally comparable in scope to the differences for $\varepsilon \Pi_{6}{ }^{\mathrm{obj}}$ versus $\varepsilon \Pi^{\mathrm{obj}}$ graphed in Figures $4 \mathrm{c}$ ) and d). The cross-sectional properties of $\varepsilon_{12}$ are also similar to those for $\varepsilon$ in Table 2.

33 The similarity of the results for $\varepsilon$ and $\varepsilon_{12}$ also suggests that recall bias is not driving the conclusions, because $\varepsilon$ and $\varepsilon_{12}$ are calculated using different realization questions with only partly overlapping reference periods. Severe recall bias would imply little overlap between these realization questions. Further, recall bias is unlikely to be correlated with monetary policy, the business cycle, and skill-biased technical change, so is unlikely to explain the results in Figures 3-5. Finally, if the systematic components in the measured forecast errors simply reflected recall bias, not actual shocks, they should not help predict consumption changes below. 
with short sample periods. In particular the business cycle and inflation regime induce lowfrequency systematic patterns in forecast errors.

Turning to the efficiency of forecasts, the demographic variables $\mathbf{Z}$ were added to the ordered probit models of $\varepsilon$ using equation (4), along with the full set of month dummies (but not yet interacting age and income by month). Table 2 records the results, starting with the discrete forecast errors in columns (1)-(4). The pseudo $\mathrm{R}^{2 \text {, }}$ are small, implying that the forecast errors are largely unsystematic, as expected. Nonetheless, according to the chi-squared statistics the demographic variables are jointly very significant, for all four discrete forecast errors, counter to the requirement of efficiency. While it is difficult to interpret individual coefficients in this context, there are some interesting patterns. As regards financial position in column (1), the errors $\varepsilon \mathrm{FP}$ tend to be more positive on average for older, higher income, and higher education (heads of) households, more negative for divorcees and minorities. Since the overall average error $\mu$ was negative (Figure 3a), the bias in the forecasts $\mathrm{QFP}^{\mathrm{e}}$ tends to decrease on average with age, income, and education.

The pattern of results is roughly similar for business conditions $\varepsilon \mathrm{BC}$ and income $\varepsilon \mathrm{Y}$ in columns (2) and (3), and often reversed in sign for inflation $\varepsilon \mathrm{P}$ (which has the opposite coding) in column (4). Columns (5)-(7) show analogous results for the continuous income and inflation variables. In all cases the demographic variables are again jointly quite significant. They are also economically significant. For instance, in column (7), the inflation forecast error is about 0.4 percentage points larger (more negative) for those without high school education, relative to those with high school education. The error is about 1.0 percentage point larger as real (1982-84 \$) household income declines from $\$ 50,000$ to $\$ 10,000$, and for minorities and females relative to whites and males. 
Whether one should interpret these results as evidence of "irrationality" is a subtle issue. It could be that young, low income, and low education people have perfectly rational expectations ex ante, but ex post happened to have received disproportionately bad shocks over the sample period. This is consistent with the literature finding increased inequality over the same period, in part due to skill-biased technical change (Cutler and Katz [1991], Attanasio and Davis [1996]). But even the ex post interpretation of the results is problematic for empirical studies that assume that time dummies capture all systematic components of forecast errors. Further, the inefficiency of the forecasts of aggregate variables (QBC, QP, and QП) is harder to explain, and more likely represents ex ante inefficiency. Even if people receive different shocks to their income and financial position, these household-specific shocks should have less effect on their forecasts of aggregate economic activity and prices.

The cross-sectional distribution of forecast errors can change over time. To illustrate, Figure 5 shows the sample average of the errors in financial position \&FP, year-by-year for different demographic groups. Since income and age are the variables interacted with time below, the figures contrast the histories of the top and bottom quartiles of the income and age distributions. In Figure 5a) for income, the errors are always more negative for low income households than for high income households, though they are more cyclical for the high income households. One interpretation is that during the expansions high income households received relatively good shocks, but low income households continued to receive somewhat negative shocks, consistent with ongoing skill-biased technical change. These results go beyond most of the literature on technical change by implying that the increased inequality was repeatedly unexpected, year after year, which has additional welfare consequences. In Figure 5b) for age, the errors for young households are both more negative and more cyclical than for older 
households. This suggests that both long-run and business cycle shocks disproportionately hit young households.

\section{Results: Excess Sensitivity and Systematic Heterogeneity in Forecast Errors}

Even if expectations are not fully rational, they might still help forecast spending. To test for excess sensitivity of consumption to sentiment, the sentiment variables $\hat{Q}$ were first imputed into the CEX using an OLS regression of equation (1). For brevity these results are not reported, but are available in the working-paper version. ${ }^{34}$ In this first-step most of the demographic variables were significant, and jointly they were very significant. In Table 3, column (1) shows the resulting adjusted $\mathrm{R}^{2} \mathrm{~s}$ from the first-step regressions. More of the level of sentiment is explained than of the forecast error (in Table 2), as expected. The dynamic variables in equation (1), namely the month dummies and their interactions with age and income, were always significant. ${ }^{35}$ The "static $\mathrm{R}^{21} \mathrm{~s}$ " in brackets in column (1) come from redoing the estimation without the dynamic variables. For all the household-specific variables $\left(\mathrm{QFP}^{\mathrm{r}}, \mathrm{QFP}^{\mathrm{e}}, \mathrm{QY}^{\mathrm{e}}\right.$ and $\mathrm{QGY}^{\mathrm{e}}$ ), the static $\mathrm{R}^{2}$ is well over half the size of the original $\mathrm{R}^{2}$, suggesting that while the dynamic variables help explain some of the variation in sentiment, the static demographic variables in $\mathbf{Z}$ are themselves quite important. The static $\mathrm{R}^{2 \text { s }}$ for the aggregate variables (QBC, QBC5, QDurs, $\mathrm{QP}^{\mathrm{e}}, \mathrm{QU}^{\mathrm{e}}$, and $\mathrm{Q}^{\mathrm{e}}$ ) are relatively smaller. Not surprisingly, respondents' expectations of aggregate variables vary less with their own (head's) demographic characteristics than do their expectations of their own financial position and income; i.e., the aggregate questions contain less cross-sectional variation.

\footnotetext{
34 The working paper reported the first-step results using ordered probit models for the discrete sentiment questions. Those results are qualitatively similar to the OLS results.
} 
Given $\hat{Q}$ one can then estimate Euler equation (3). The resulting excess sensitivity coefficients $b_{2}$ appear in columns (2) and (3) of Table 3, for both nondurable and total consumption. ${ }^{36}$ Over half of the coefficients are significant, counter to the PIH. While the magnitudes are usually larger for total consumption, the results for nondurables are generally as significant. The signs on $b_{2}$ are always negative, except for inflation and unemployment for which the coding was reversed. Thus, in all cases the better states are associated with less steep consumption profiles; that is, higher confidence is associated with less saving. This outcome is consistent with precautionary motives for saving (Deaton [1992], Carroll [1992], Lusardi [1998]) as well as increases in expected future resources. ${ }^{37}$

Most of the insignificant excess sensitivity coefficients are for questions referring to aggregate variables, $\mathrm{QBC}, \mathrm{QDurs}, \mathrm{QP}^{\mathrm{e}}$, and $\mathrm{QU}^{\mathrm{e}}$. In part this is the result of their having less cross-sectional variation, conditional on the time dummies, as evidenced by their smaller firststep static $\mathrm{R}^{2}$ s. Conversely, almost all the household-specific variables generate significant excess sensitivity. ${ }^{38}$ Thus, the cross-sectional information in sentiment appears to help predict consumption.

There are many possible sources of this excess sensitivity. One specific alternative hypothesis that has not so far received much attention is systematic heterogeneity in forecast

\footnotetext{
35 To ease the computational demands the quadratic term in age has been dropped. Preliminary analysis suggested that for most sentiment questions the quadratic term did not vary as significantly across time.

${ }^{36}$ The coefficients on the demographic variables $\mathbf{W}$ in equation (3) are similar to those in related studies using the CEX, e.g. Souleles [1999], and so are not reported. In short, the coefficients on changes in family size are generally positive; the coefficients on age are less significant.

${ }^{37}$ It remains unclear whether people's answers to the sentiment questions (other than QY and QGY) reflect expected future uncertainty or expected future levels of income and other resources. Carroll, Fuhrer, and Wilcox [1994] show that the aggregate ICS reflects more than just the level of expected income. Also, as already noted, outside the PIH a flatter consumption profile need not necessarily imply less saving.

38 Even though QFP $^{\mathrm{r}}$ does not ask about the future, time-series studies have similarly found the coincident component of the aggregate ICS index (QFP $\left.{ }^{\mathrm{r}}+\mathrm{QDurs}\right)$ to be useful in forecasting (e.g., Throop [1992]).
} 
errors. ${ }^{39}$ This is especially likely to be a problem since both sentiment and forecast errors have just been found to be correlated with the same household demographic characteristics. These findings suggest that even a long sample period and a full set of time dummies might not be enough to ensure orthogonality of the forecast errors with the sentiment regressors. Since the forecast errors are likely to be correlated with many regressors of interest, this would be a general problem.

To verify this suggestion directly, estimates of the forecast errors $\hat{\varepsilon}$ were added to Euler equation (3), for the variables for which there are matching realization and expectation questions. Table 4 shows the results, imputing the forecast errors using equation (4) (now interacting age and income by month): $\hat{\varepsilon}_{\mathrm{t}+1}=\overbrace{Q^{r}{ }_{t+1}-Q^{e}}{ }_{t}$. Despite the time dummies in equation (3), the coefficients $b_{3}$ on the errors $\hat{\varepsilon}$ are sometimes significant. Except for inflation, when they are significant they are positive: positive innovations in financial position, income, etc., are correlated with increases in consumption, as expected. For the inflation questions QP and QП, with the opposite coding, the coefficients are negative. But even controlling for the forecast errors, the excess sensitivity regressor $b_{2}$ remains significantly negative for two of the household-specific variables, $\mathrm{QFP}^{\mathrm{e}}$ and $\mathrm{QGY}^{\mathrm{e}}$ (in rows (1) and (5)). That is, some excess sensitivity persists and so is not due to heterogeneity in forecast errors alone ${ }^{40}$ On the other

\footnotetext{
39 Another possible source of the excess sensitivity is unobserved differences in discount factors and other household fixed effects. Following Runkle [1991], lagged consumption growth from households' first interview was added to equation (3) to control for household fixed effects, at the cost of a loss of power. Nonetheless over half of the significant coefficients for nondurable consumption in Table 3 remain significant, including $\mathrm{QFP}^{\mathrm{e}}, \mathrm{QBC5}$, and $\mathrm{QY}^{\mathrm{e}}$. While $\mathrm{QFP}^{\mathrm{r}}$ and $\mathrm{Q}^{\mathrm{e}}$ become less significant, $\mathrm{QP}^{\mathrm{e}}$ becomes more significant. Hence, heterogeneous discount factors and other fixed effects cannot alone be generating the estimated excess sensitivity. Further, Hausman tests and autocorrelation tests of the residuals produce little evidence for the presence of fixed effects, consistent with the previous literature (Browning and Lusardi [1996]).

40 Of course it is possible that even the remaining excess sensitivity is spurious, due to other systematic heterogeneity in forecast errors that matters for consumption but is not controlled for by the sentiment variables (or due to other sources of mispecification, such as intertemporal nonseparability or liquidity constraints). However,
} 
hand, $\mathrm{b}_{2}$ has become insignificant for the third household-specific variable $Q Y^{\mathrm{e}}$, as well as for $\mathrm{QBC}^{\mathrm{e}}, \mathrm{QP}^{\mathrm{e}}$, and $\mathrm{Q}^{\mathrm{e}}$. Hence some of the excess sensitivity appears to be due to systematic heterogeneity in forecast errors. This suggests the possibility that previous excess sensitivity tests might have made spurious inferences.

The forecast errors were also computed by first separately imputing the realizations and expectations $\hat{Q}^{\mathrm{r}}{ }_{\mathrm{t}+1}$ and $\hat{Q}_{\mathrm{t}}^{\mathrm{e}}$ in the CEX using equation (1), and then taking their difference: $\hat{\varepsilon}_{\mathrm{t}+1}$ $=\hat{Q}^{\mathrm{r}}{ }_{\mathrm{t}+1}-\hat{Q}_{\mathrm{t}}^{\mathrm{e}}$. The results are generally similar, and appear in the working paper. ${ }^{41}$ In sum, however one controls for the forecast errors, there remains significant excess sensitivity, especially for the household-specific variables regarding financial position and income.

\section{Conclusion}

This paper provided perhaps the first comprehensive analysis of the household data underlying the Michigan Index of Consumer Sentiment. This data allowed for a cleaner test of the rationality of consumers' expectations than in most previous studies. The results can also be interpreted as characterizing the shocks that hit different types of households over time. Expectations appear to be biased, at least ex post, in that forecast errors do not average out even over a sample period lasting almost 20 years. This bias is not constant over time; it is related to

shocks to income, financial position, aggregate economic activity and prices must be among the most important sources of innovations to consumption. Further, as already noted, under the null hypothesis that forecast errors are classical, they should be orthogonal to other factors in agents' information sets, including discount rates. Hence the effect in Table 4 of adding forecast errors to the Euler equation cannot be due to such factors.

41 (When the realization questions $\mathrm{Q}^{\mathrm{r}}$ are not available for much of the sample, the change in the estimated expectational variable was used instead: $\hat{\varepsilon}_{\mathrm{t}+1}=\hat{Q}_{\mathrm{t}+1}^{\mathrm{e}}-\hat{Q}_{\mathrm{t}}^{\mathrm{e}}$. A change in expectations over time still represents an innovation.) The second set of forecast errors $\hat{\varepsilon}$ using equation (1) are generally less significant in the Euler equation than those reported in Table 4, perhaps because the imputed variables $\hat{Q}$ do not vary enough across quarters. Still, $\hat{\varepsilon}$ is significantly positive for $\mathrm{QY}^{\mathrm{e}}$. Also the excess sensitivity coefficients $\mathrm{b}_{2}$ for $\mathrm{QFP}^{\mathrm{e}}$ and $\mathrm{QGY}^{\mathrm{e}}$ remain significant, and now are significant for $\mathrm{QY}^{\mathrm{e}}$. Again the excess sensitivity coefficients are generally insignificant for the aggregate variables, with the exception of $\mathrm{Q}^{\mathrm{e}}$. 
the inflation regime and the business cycle. People underestimated the disinflation of the early 1980 's and in the 1990's, and generally appear to underestimate the amplitude of business cycles. Expectations are also inefficient, in that people's forecast errors are correlated with their demographic characteristics and/or aggregate shocks did not hit all people uniformly. For instance, during expansions high income households received relatively good shocks, but low income households continued to receive somewhat negative shocks, consistent with ongoing, unexpected skill-biased technical change. Whether one interprets these results as evidence of ex ante "irrationality" or not, they are problematic for empirical studies that have short sample periods or assume that time dummies control for all systematic components of forecast errors. Empirical implementations of forward-looking models need to recognize that forecast errors are more complex than usually assumed.

Attention then turned to whether the sentiment data helps predict household expenditure. Significant evidence of excess sensitivity was found, counter to the PIH. Higher confidence was correlated with less saving, consistent with precautionary motives and increases in expected future resources. Further, this paper provided a unique test of the specific alternative hypothesis that systematic heterogeneity in forecast errors explains the rejection of the PIH. Previous studies, lacking explicit measures of these errors, have not been able to consider this hypothesis directly. Demographic components of forecast errors were found to explain some, but not all, of the excess sensitivity. More broadly, because forecast errors are correlated with household demographic characteristics, they will be correlated with many regressors of interest in forwardlooking models, suggesting that non-classical forecast errors are in practice a general and serious problem. Finally, the cross-sectional variation in sentiment, net of time dummies, was itself found to be informative. This is information lost in the aggregated ICS time series for sentiment; 
nor is it contained in any other macro variable available for forecasting. Of the Michigan survey questions, those asking specifically about the household, rather than the aggregate economy, were generally found to contain the most useful cross-sectional information.

This analysis can be extended in a number of ways. First, given the significance of the cross-sectional distribution of sentiment, new sentiment time series might be created to better incorporate this distribution, for instance by taking weighted averages of sentiment across households. ${ }^{42}$ Second, one can similarly examine many other economic decisions in addition to spending for which expectations matter, as in the portfolio study of Souleles [1999b]. Crosssectional data is especially well suited to studying the effects of one-time events, like the 1987 stock market crash. Third, durables purchases might be modeled more explicitly, taking into account their discreteness.

\footnotetext{
42 The weights could reflect e.g. the scale of spending by different groups of people, or the sensitivity of their spending to their sentiment.
} 


\section{Data Appendix}

\section{A. The CAB.}

The additional sentiment questions, not part of the ICS, include the following:

$\mathrm{QBC}^{\mathrm{r}}$. Would you say that at the present time business conditions are better or worse than they were a year ago? [better now, about same, worse now]

$\mathrm{QBC}^{\mathrm{e}}$. And how about a year from now, do you expect that in the country as a whole, business conditions will be better or worse than they are at present, or just about the same? [better a year from now, about same, worse a year from now]

$\mathrm{QY}^{\mathrm{r}}$. During the last year or two, would you say that your (family) income went up more than prices, went up about the same as prices, or went up less than prices? [more, same, less]

QY ${ }^{\mathrm{e}}$. During the next year or two, do you expect that your (family) income will go up more than prices will go up, about the same, or less than prices will go up? [more, same, less]

$\mathrm{QP}^{\mathrm{r}}$. During the last 12 months, have prices of the things you buy remained unchanged, or have they gone up, or have they gone down? [gone up, remained unchanged, gone down]

$\mathrm{QP}^{\mathrm{e}}$. During the next 12 months, do you think that prices in general will go up, or down, or stay where they are now? [go up, will not go up, go down]

$\mathrm{QU}^{\mathrm{e}}$. How about people out of work during the coming 12 months - do you think that there will be more unemployment than now, about the same, or less? [more, about same, less]

$\mathrm{QGY}^{\mathrm{r}}$. [The growth rate is computed from changes in the level of income from the following question:] Now, thinking about your (family's) total income from all sources (including your job), how much did you (your family) receive in [the previous calendar year]?

$\mathrm{QGY}^{\mathrm{e}}$. By what percent do you expect your (family) income to (increase/decrease) during the next 12 months?

$\mathrm{Q} \Pi^{\mathrm{r}}$. By about what percent do you think prices have gone (up/down) on the average, during the last 12 months?

$\mathrm{Q} \Pi^{\mathrm{e}}$. By about what percent do you expect prices to go (up/down) on the average, during the next 12 months?

Other answers such as "Don't Know" are also allowed, but are not used here. When the answers to QП and QGY were topcoded, they were not used.

For $\mathrm{CAB}$ interviews that took place in more than one installment, if these installments spanned two different calendar months, the second month is used to date the observation. If any demographic variable used in a regression is missing, topcoded, or flagged (e.g., "Don't Know"), the observation is not used. For the demographic variables $\mathbf{Z}$, when the continuous measure of total household income was missing, the midpoint of the bracketed income variable was used instead. (But the bracketed variable is not used in computing the growth rate of income.) The reference period for realized income (used in computing the growth rate $\mathrm{QGY}^{\mathrm{r}}$ ) is the previous calendar year, whereas for the CEX it is the past 12 months. For consistency CAB income was deflated using the CPI (1982-84 \$) for the past 12 months. Since the original CAB income variable is constrained to be positive, for consistency total income in the CEX was used only 
when positive and not flagged. Sample selection is discussed in the text.

\section{B. The CEX.}

In aggregating individual expenditures, if any component of total consumption or nondurable consumption was topcoded or missing its cost, the whole consumption group was set to missing. If any component was missing its date or dated before the reference period, the group was dropped for all interviews for the household at issue. A large number of expenditures are dated in the month of the interview. Following the recommendation of the staff at the BLS, for consistency such expenditures were accrued to the following reference period.

In addition to the sample restrictions in the text, an observation is dropped if the age of the head increases by more than one, or decreases, on moving into the next quarter. An observation is also dropped if the age of any other member changes in this way and thereby results in the member's switching between being a kid (less than 16 years old) and an adult (at least 16). If any variable used in a regression is missing, the observation is not used. Other sample restrictions are described in the text. 


\section{References}

Acemoglu, D., and Scott, A., 1994, "Consumer Confidence and Rational Expectations: Are Agents’ Beliefs Consistent with the Theory?” Economic Journal, 104, pp. 1-19.

Alessie, R. and Lusardi, A., 1997, "Saving and income smoothing: Evidence from panel data", European Economic Review, 41, pp. 1251-1279.

Angrist, J. and Krueger, A., 1992, "The Effect of Age at School Entry on Educational Attainment: An Application of Instrumental Variables with Moments from Two Samples", Journal of the American Statistical Association, 87, pp. 328-336.

Attanasio, O., and Davis, S., 1996, "Relative Wage Movements and the Distribution of Consumption," Journal of Political Economy, 104(6), December, pp. 1227-62.

Attanasio, O., and Weber, G., 1995, "Is Consumption Growth Consistent with Intertemporal Optimization? Evidence from the Consumer Expenditure Survey," Journal of Political Economy, 95, pp. 1121-1157.

Batchelor, R., 1986, “Quantitative v. Qualitative Measures of Inflation Expectations,” Oxford Bulletin of Economic and Statistics, 48, pp. 99-120.

Batchelor, R., and Jonung, L., 1989, "Cross-Sectional Evidence on the Rationality of the Mean and Variance of Inflation Expectations," in Grunert, Klaus G., ed., 1989, Understanding Economic Behavior, Boston: Kluwer press, pp. 93-105.

Browning, M., and Lusardi, A., 1996, "Household Saving: Micro Theories and Micro Facts," Journal of Economic Literature, v34, December, pp. 1797-1855.

Burch, S., and Gordon, S., 1985, “The Problem of Inference in Consumer Surveys," Federal Reserve Board of Governors working paper, May.

Carroll, C., 1992, "The Buffer-Stock Theory of Saving: Some Macroeconomic Evidence," Brookings Papers on Economic Activity, 2, pp. 61-156.

Carroll, C., Fuhrer, J., and Wilcox, D., 1994, "Does Consumer Sentiment Forecast Household Spending? If So, Why?,” American Economic Review, 84, pp. 1397-1408.

Carroll, C., Dynan K., and Krane, S., 1996, "Balance Sheets and Precautionary Saving," Federal Reserve Board of Governors working paper, January.

Chamberlain, G., 1984, "Panel Data," in Griliches, Z., and Intriligator, M., Handbook of Econometrics, Amsterdam: North-Holland.

Croushore, D., 1998, "Evaluating Inflation Forecasts," Federal Reserve Bank of Philadelphia working paper, June. 
Cutler, D., and Katz, L., 1991, "Macroeconomic Performance and the Disadvantaged," Brookings Papers on Economic Activity, 0(2), pp. 1-61.

Das, M., and van Soest, A., 1996, "A Panel Data Model for Subjective Information on Household Income Growth," Tilburg University working paper, June.

Deaton, A., 1992, Understanding Consumption, Oxford: Oxford University Press.

Dominitz, J., 1993, "Subjective Expectations of Unemployment, Earnings, and Income," University of Wisconsin-Madison working paper, November.

Dynan, K., 1993, "How Prudent Are Consumers?" Journal of Political Economy, 101, December, pp. 1104-13.

Flavin, M., 1991, "The Joint Consumption/Assets Demand Decision: A Case Study in Robust Estimation,” NBER working paper \#3802.

Friend, I., and Adams, G., 1964, "The Predictive Ability of Consumer Attitudes, Stock Prices, and Non-Attitudinal Variables," Journal of the American Statistical Association, 59, December, pp. 987-1005.

Gramlich, E., 1983, "Models of Inflation Expectations Formation," Journal of Money, Credit, and Banking, 15, pp. 155-173.

Hall, R., and Mishkin, F., 1982, "The Sensitivity of Consumption to Transitory Income: Estimates from Panel Data on Households," Econometrica, 50, March, pp. 461-82.

Jappelli, T., Pischke, S., and Souleles, N., 1998. "Testing for Liquidity Constraints in Euler Equations with Complementary Data Sources," The Review of Economics and Statistics, 80(2), pp. 251-262.

Keane, M., and Runkle, D., 1990, "Testing the Rationality of Price Forecasts: New Evidence from Panel Data," American Economic Review, 80, pp. 714-735.

Ludvigson, S., 1996, "Consumer Sentiment and Household Expenditure: Reevaluating the Forecasting Equations," Federal Reserve Bank of New York working paper, November.

Ludvigson, S., and Paxson, C., 1997, "Approximation Bias in Linearized Euler Equations," Federal Reserve Bank of New York working paper, March.

Lusardi, A., 1996, "Permanent Income, Current Income and Consumption: Evidence from Two Panel Data Sets," Journal of Business and Economic Statistics, 14, pp. 81-90.

Lusardi, A., 1998, "On the Importance of the Precautionary Saving Motive," American Economic Review, May. 
Maddala, G., Fishe, R., and Lahiri, K., 1981, “A Time Series Analysis of Popular Expectations Data," in Zellner, A., ed., 1983, Applied Time Series Analysis of Economic Data, U.S. Department of Commerce, pp. 278-290.

Mariger, R., and Shaw, K., 1993, "Unanticipated Aggregate Disturbances and Tests of the LifeCycle Consumption Model Using Panel Data," Review of Economics and Statistics, pp. 48-56.

McNeil, J., 1974, "Federal Programs to Measure Consumer Purchase Expectations, 1946-1973: A Post-Mortem," Journal of Consumer Research, 1, pp. 1-10.

Runkle, D., 1991, "Liquidity Constraints and the Permanent-income Hypothesis," Journal of Monetary Economics, 27, pp. 73-98.

Shapiro, M. and Slemrod, J., 1995, "Consumer Response to the Timing of Income: Evidence from a Change in Tax Withholding." American Economic Review, 85(1), March, pp. 274-283.

Souleles, S., 1999, "The Response of Household Consumption to Income Tax Refunds," American Economic Review, forthcoming.

Souleles, S., 1999b, "Household Securities Purchases, Transactions Costs, and Hedging Motives," University of Pennsylvania working paper, August.

Thomas, L., 1999, "Survey Measures of Expected U.S. Inflation," Journal of Economic Perspectives, 13(4), pp. 125-144.

Throop, A., 1992, "Consumer Sentiment: Its Causes and Effects,” Economic Review, 1, Federal Reserve Bank of San Francisco, pp. 35-59.

Zeldes, S., 1989, "Consumption and Liquidity Constraints: An Empirical Investigation," Journal of Political Economy, 97, pp. 305-346. 
Figure 1: Monthly Averages of $\mathrm{QFP}^{\mathrm{r}}$ and $\mathrm{QFP}^{\mathrm{e}}$

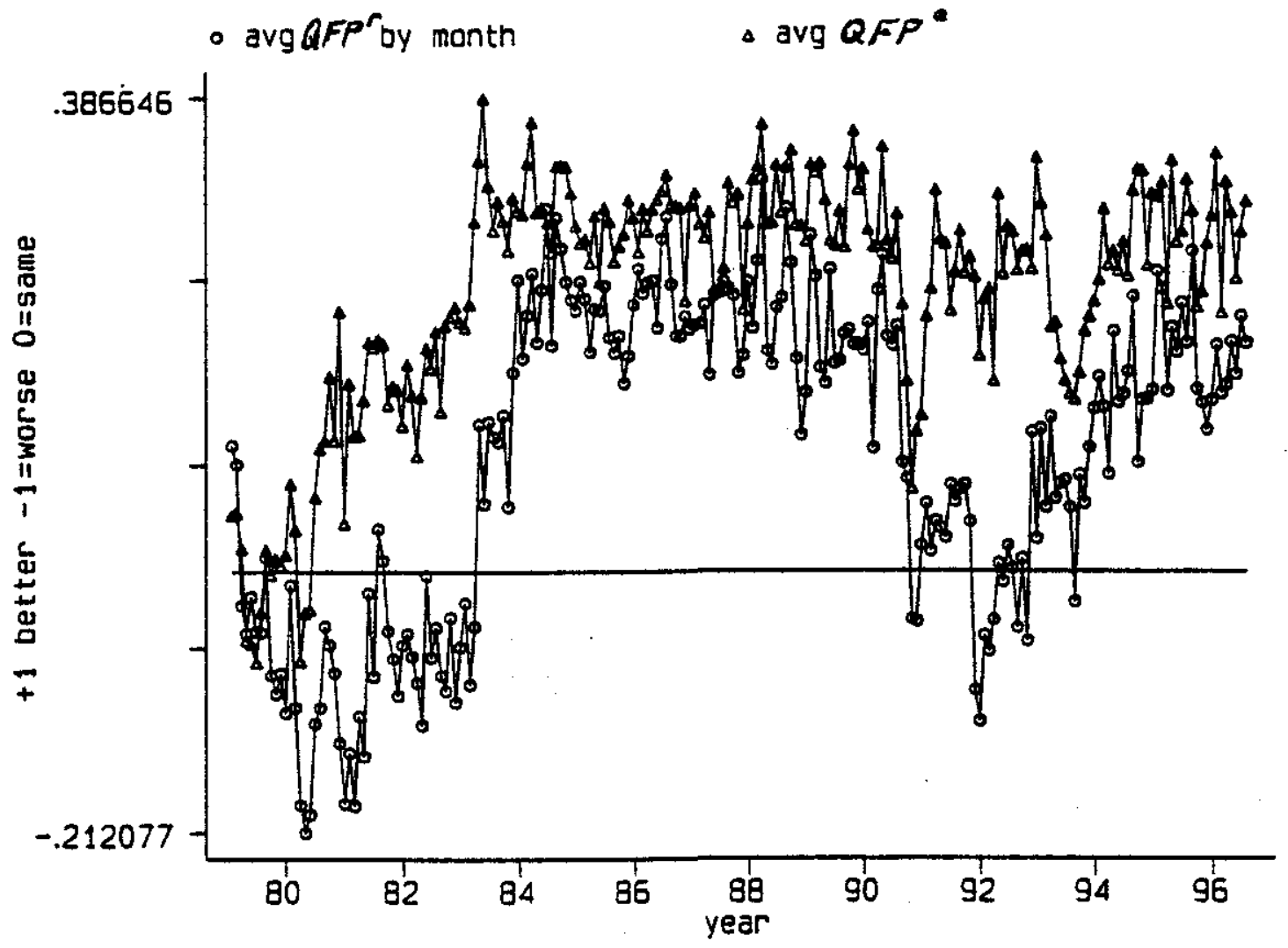

Figure 2: Monthly Averages of QBC, QBC5, QDurs
- avg $Q B C$
$\triangle$ avg Qac5

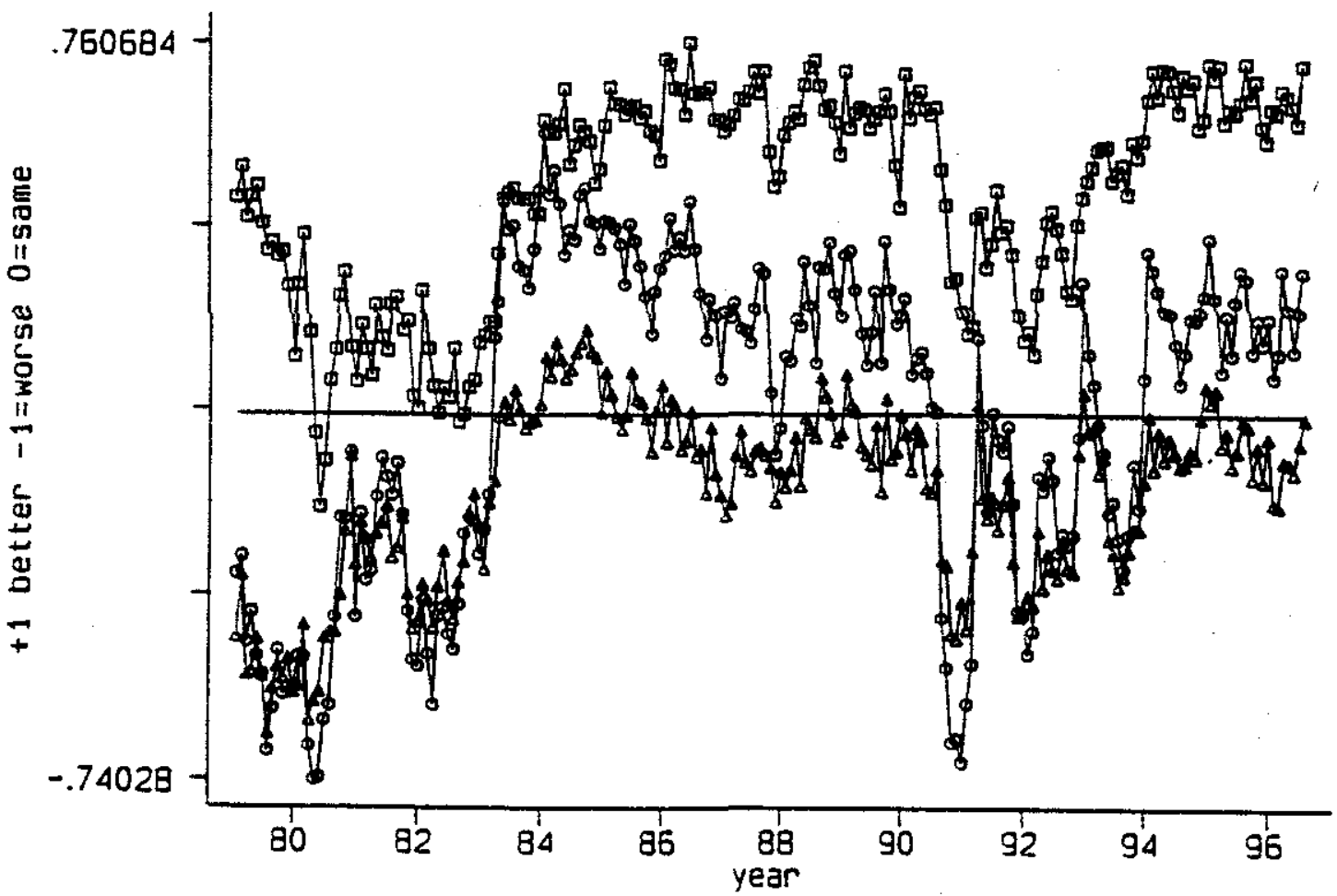


Figure 3: $\quad$ Bias and Time Effects in Forecast Errors

Discrete CAB Variables

a) Financial Position: $\varepsilon F P=\mathrm{QFP}_{2}^{\mathrm{r}}-\mathrm{QFP}_{1}^{\mathrm{e}}$

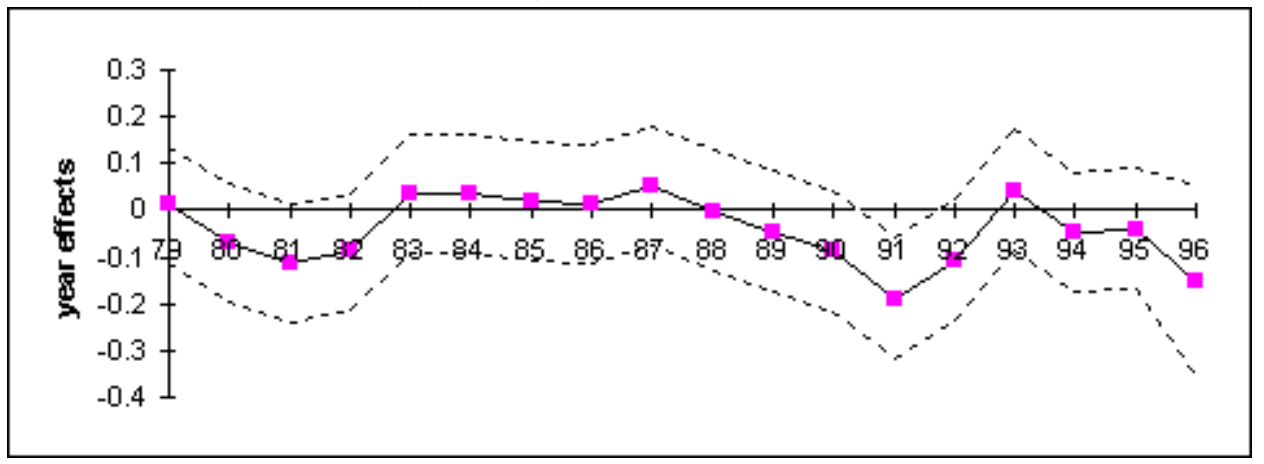

\# obs $=42767$

Pseudo $\mathrm{R}^{2}=.01$

$\chi^{2}(18)=158$, pval $=0.00$

$\mu=-.064(.007)$

b) Business Conditions: $\quad \varepsilon B C=\mathrm{QBC}_{2}^{\mathrm{r}}-\mathrm{QBC}_{1}^{\mathrm{e}}$

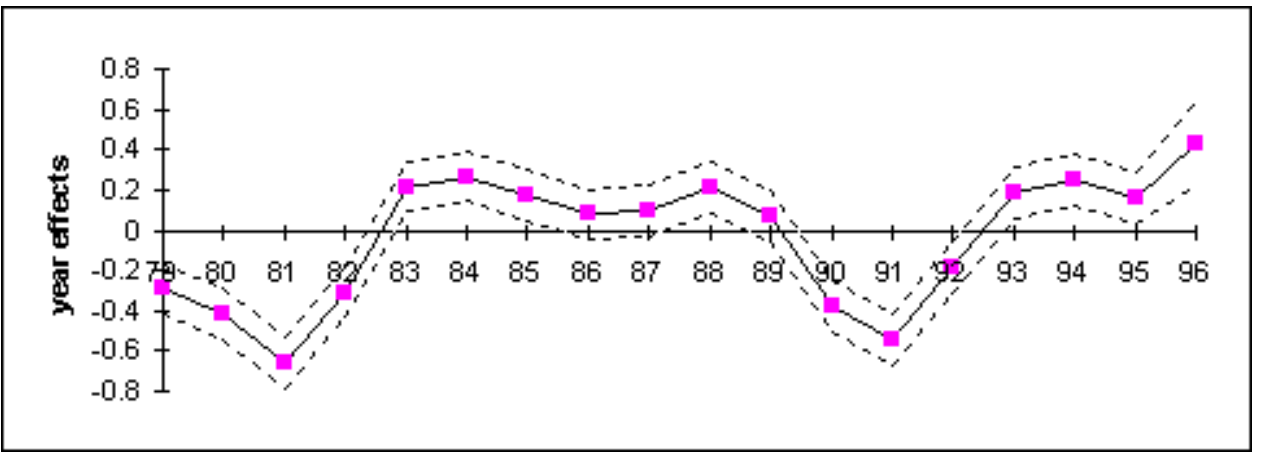

\# obs $=42645$

Pseudo $\mathrm{R}^{2}=.03$

$\chi^{2}(18)=3325, \mathrm{pval}=0.00$

$\mu=-.105(.026)$

c) Income: $\quad \varepsilon \mathrm{Y}=\mathrm{QY}_{2}^{\mathrm{r}}-\mathrm{QY}_{1}^{\mathrm{e}}$

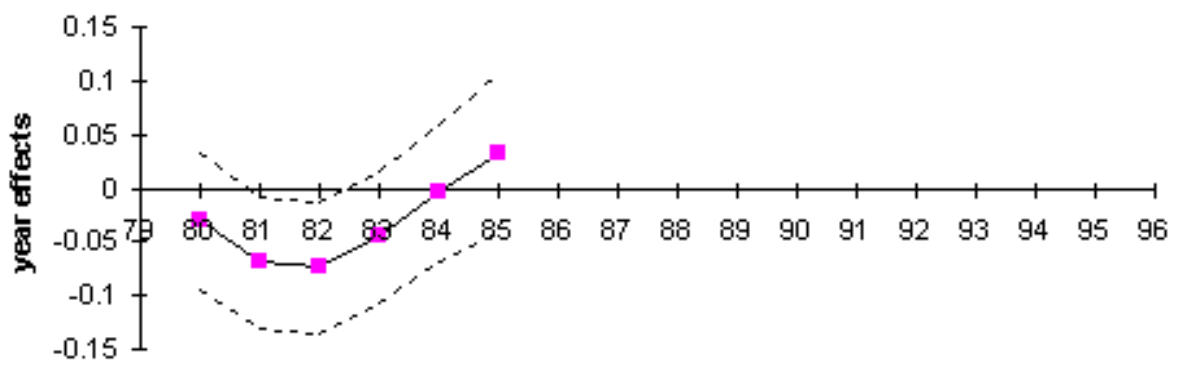

$\#$ obs $=17503$

Pseudo $\mathrm{R}^{2}=.01$

$\chi^{2}(6)=17.2$, pval $=0.01$

$\mu=-.085(.008)$

d) Inflation: $\varepsilon \mathrm{P}=\mathrm{QP}^{\mathrm{r}}{ }_{2}-\mathrm{QP}^{\mathrm{e}}{ }_{1}$

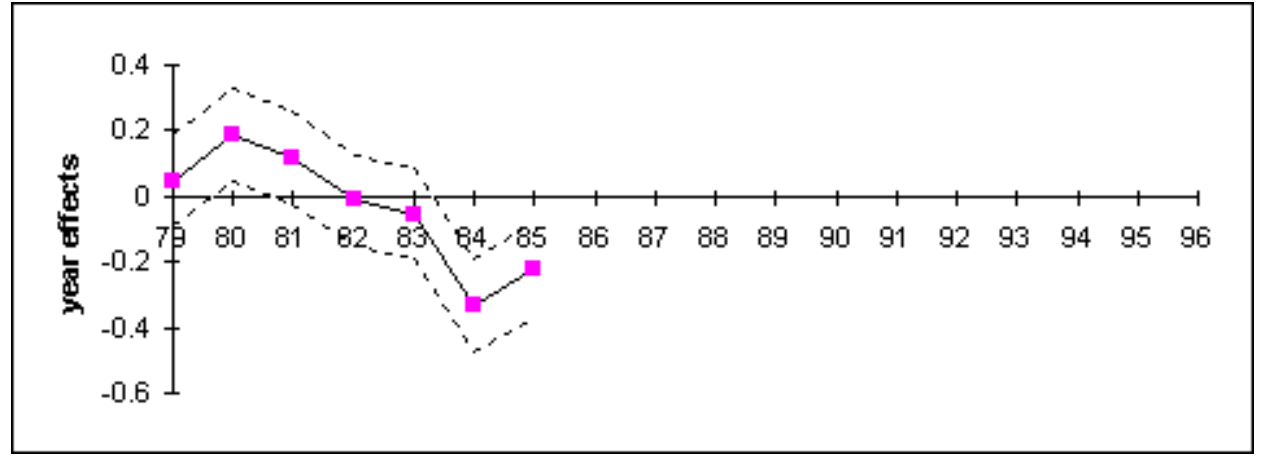

$\#$ obs $=19577$

Pseudo $\mathrm{R}^{2}=.01$

$\chi^{2}(7)=349, \mathrm{pval}=0.00$

$\mu=.056$ (.012) 
Notes:

- For variable and sample definitions see the notes for Table 2.

- The graphed results come from an ordered probit of the forecast errors $\varepsilon$ in $\{-2,-1,0,1,2\}$ on year dummies.

The

middle line gives the estimated coefficients on the year dummies (in the latent index function). The outside dashed lines represent $95 \%$ confidence intervals. $\chi^{2}$ tests the joint significance of the year effects.

- To calculate the mean forecast error $\mu$, the errors $\varepsilon$ are regressed by OLS on a constant, correcting the standard errors for heteroscedasticity and cross-correlation within the month. 
Figure 4: $\quad$ Bias and Time Effects in Forecast Errors

\section{Continuous CAB Variables}

a) Income error: $\varepsilon \mathrm{GY}=\mathrm{QGY}_{2}^{\mathrm{r}}{ }_{2}-\mathrm{QGY}_{1}^{\mathrm{e}}$

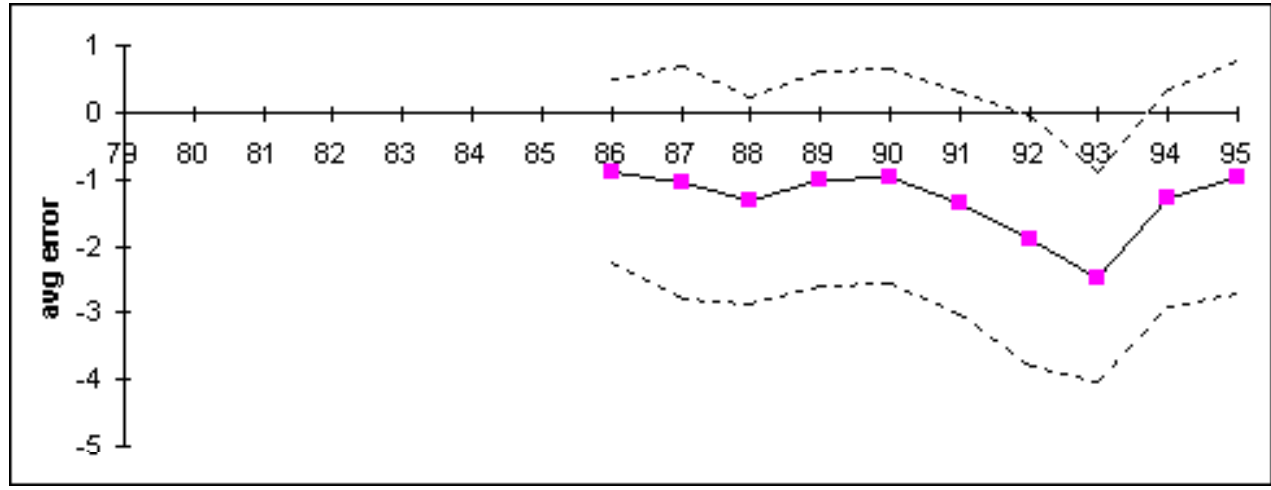

$\#$ obs $=6757$

$\mathrm{R}^{2}=.01$

$\mathrm{F}=2.9$, pval $=0.01$

$\mu=-1.31(.24)$

b) Inflation error (subjective): $\varepsilon \Pi^{\text {subj }}=\mathrm{Q}^{\mathrm{r}}{ }_{2}-\mathrm{Q} \Pi_{1}^{\mathrm{e}}$

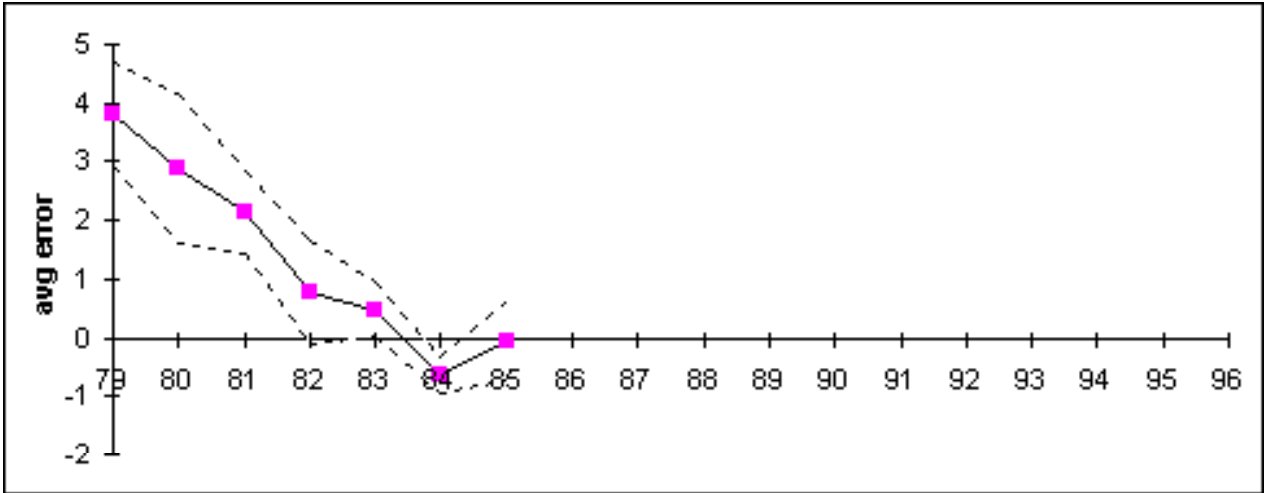

\# obs $=17650$

$\mathrm{R}^{2}=.04$

$\mathrm{F}=23$, pval $=0.00$

$\mu=1.53(.25)$

c) Inflation error (objective): $\varepsilon \Pi^{\mathrm{obj}}=\Pi_{12}-\mathrm{Q} \Pi_{1}^{\mathrm{e}}$

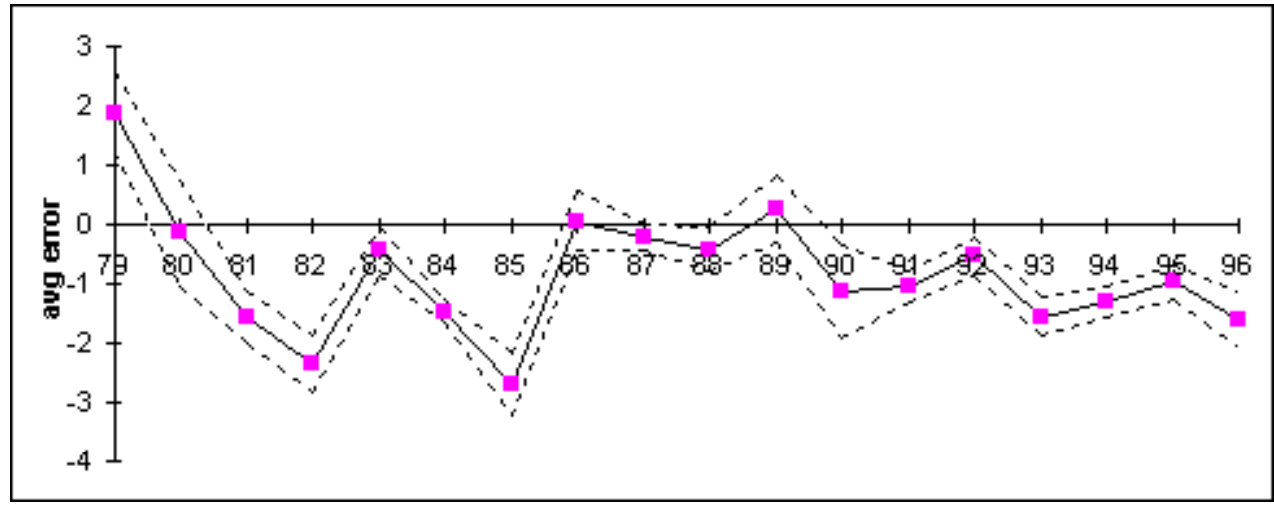

$\#$ obs $=124724$

$\mathrm{R}^{2}=.04$

$\mathrm{F}=51$, pval $=0.00$

$\mu=-0.50(.13)$

d) Inflation error (objective, 6 month horizon): $\varepsilon \Pi_{6}{ }^{\text {obj }}=\Pi_{6}-\mathrm{Q} \Pi^{\mathrm{e}}$

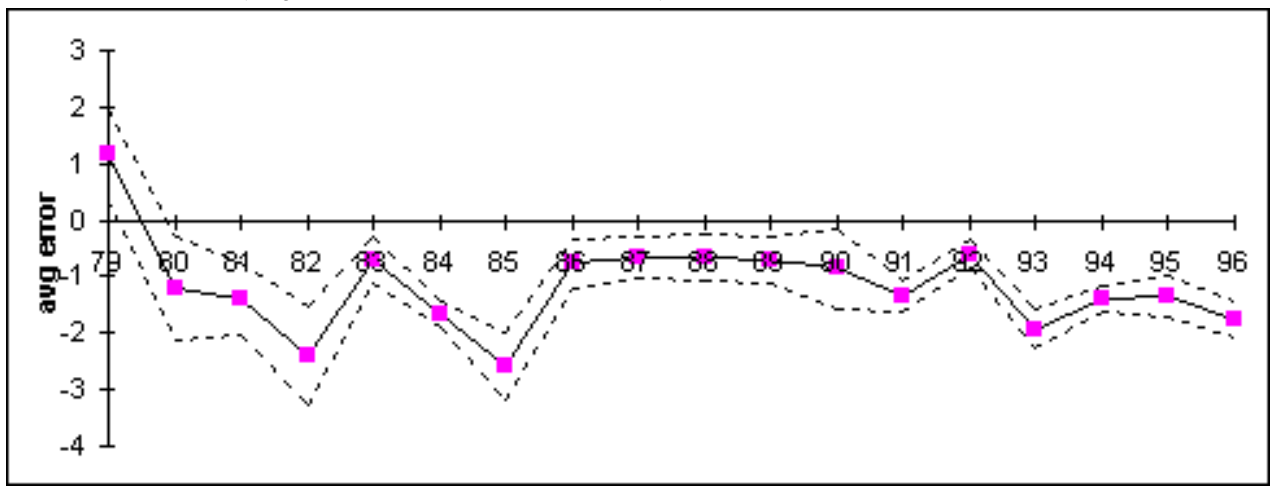

\# obs $=125178$

$\mathrm{R}^{2}=.03$

$\mathrm{F}=29, \mathrm{pval}=0.00$

$\mu=-0.95(.13)$ 
Notes:

- For variable and sample definitions see the notes for Table 2.

- The graphed results come from an OLS regression of the forecast errors $\varepsilon$ on year dummies, correcting the standard errors for heteroscedasticity and cross-sectional correlation within the month. The middle line records

the year effects, the outside dashed lines the $95 \%$ confidence intervals. F tests the joint significance of the year effects.

- To calculate the mean forecast error $\mu$, the errors $\varepsilon$ are regressed by OLS on a constant, correcting the standard errors for heteroscedasticity and cross-correlation within the month. 
Figure 5: Time Effects in Forecast Errors, by Demographic Groups

Financial Position \&FP

a) by Income

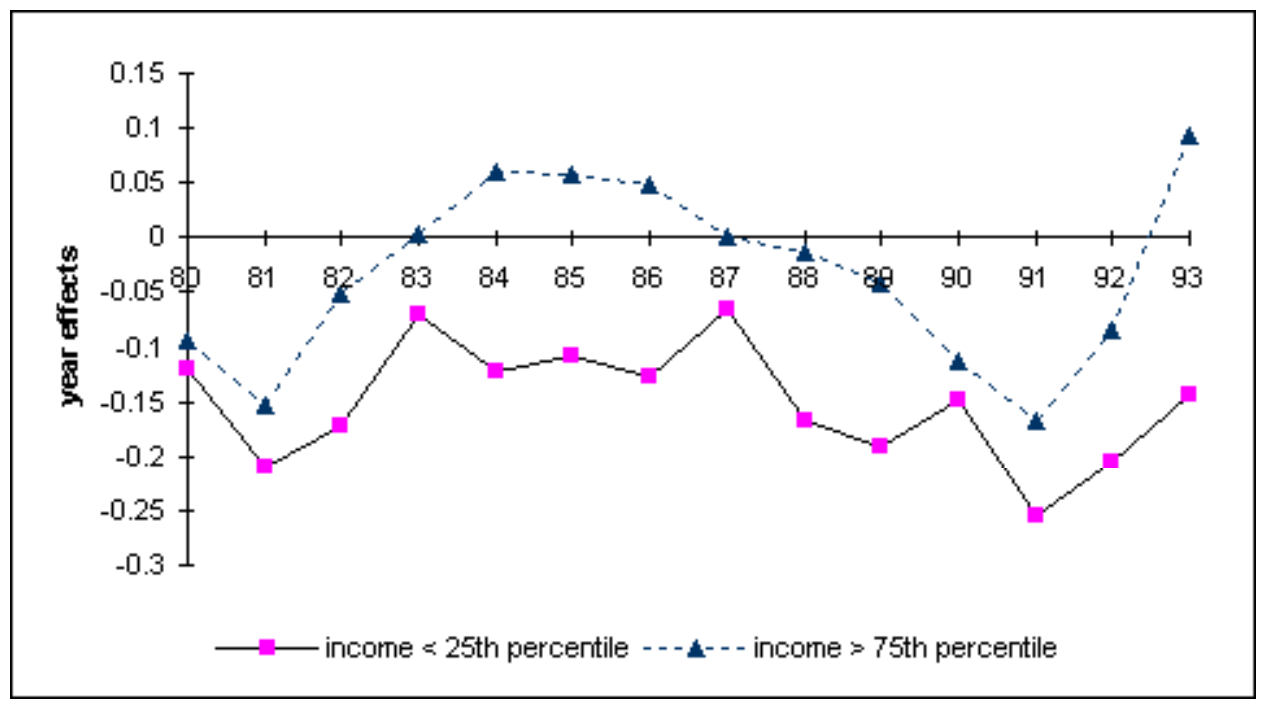

b) by Age

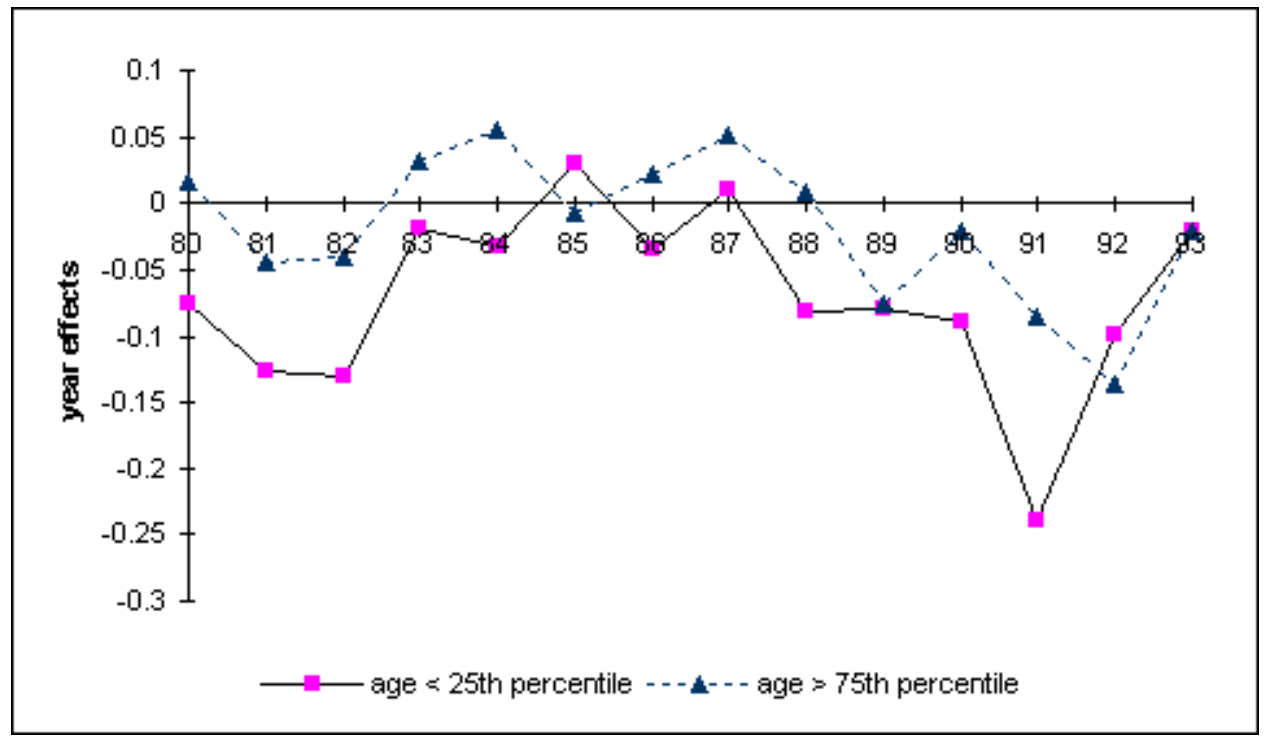

Notes:

- The figures graph the sample average of the error in financial position (See Table 2.) for the bottom and top quarters of the income and age distributions. 


\section{Table 1: Sample Means}

1982-1993

\begin{tabular}{|c|c|c|}
\hline & $\mathrm{CAB}$ & CEX \\
\hline age & 45.5 & 48.7 \\
\hline $\ln$ (income) & 9.93 & 9.97 \\
\hline married & 0.567 & 0.583 \\
\hline separated & 0.269 & 0.288 \\
\hline nonwhite & 0.093 & 0.116 \\
\hline female head & 0.252 & 0.282 \\
\hline no high school & 0.165 & 0.243 \\
\hline some college & 0.261 & 0.217 \\
\hline college & 0.279 & 0.237 \\
\hline 1 kid & 0.154 & 0.155 \\
\hline 2 kids & 0.150 & 0.145 \\
\hline 3+ kids & 0.081 & 0.083 \\
\hline 2 adults & 0.526 & 0.552 \\
\hline $3+$ adults & 0.101 & 0.125 \\
\hline midwest & 0.284 & 0.262 \\
\hline south & 0.322 & 0.287 \\
\hline west & 0.201 & 0.237 \\
\hline \# obs & 54488 & 97993 \\
\hline
\end{tabular}

Notes:

- The omitted categorical variables are: single, white, male head, high school graduate, no kids, one adult, northeast. Income is real household income (1982-84 \$).

- For comparison the CAB sample period is restricted to the CEX sample period, 1982-93. The actual samples used in the different analyses in the paper can differ somewhat due to missing data or additional sample restrictions, as explained in the text and the following tables. 
Table 2: $\quad$ Efficiency: Cross-sectional Variation in Forecast Errors

\section{CAB Surveys, 1978-96}

(1)

\begin{tabular}{|c|c|c|c|}
\hline$\varepsilon F P=Q F^{r}{ }_{2}-\mathrm{QFP}_{1}^{\mathrm{e}}$ & $\varepsilon B C=Q B^{r}{ }_{2}-Q B^{e}{ }_{1}$ & $\varepsilon \mathrm{Y}=\mathrm{QY}_{2}^{\mathrm{r}}-\mathrm{QY}_{1}^{\mathrm{e}}$ & $\varepsilon \mathrm{P}=\mathrm{QP}_{2-}^{\mathrm{r}}-\mathrm{QP}_{1}^{\mathrm{e}}$ \\
\hline
\end{tabular}

\begin{tabular}{|c|c|c|c|c|c|c|c|c|c|c|c|c|}
\hline age & -0.018 & 0.003 & $* *$ & -0.010 & 0.003 & $* *$ & -0.016 & 0.005 & $* *$ & 0.003 & 0.005 & \\
\hline $\mathrm{age}^{2} / 100$ & 0.020 & 0.003 & $* *$ & 0.005 & 0.003 & $*$ & 0.018 & 0.005 & $* *$ & 0.007 & 0.005 & \\
\hline $\ln$ (income) & 0.067 & 0.011 & $* *$ & -0.007 & 0.011 & & 0.071 & 0.019 & $* *$ & -0.050 & 0.020 & $* *$ \\
\hline married & -0.016 & 0.041 & & 0.037 & 0.041 & & 0.097 & 0.065 & & 0.090 & 0.069 & \\
\hline separated & -0.074 & 0.026 & $* *$ & 0.051 & 0.026 & $* *$ & -0.018 & 0.040 & & -0.027 & 0.043 & \\
\hline nonwhite & -0.119 & 0.026 & $* *$ & -0.031 & 0.025 & & -0.065 & 0.041 & & 0.128 & 0.043 & $* *$ \\
\hline female & 0.005 & 0.023 & & -0.025 & 0.023 & & -0.001 & 0.036 & & 0.146 & 0.038 & $* *$ \\
\hline no high school & -0.021 & 0.023 & & -0.025 & 0.023 & & -0.008 & 0.035 & & 0.038 & 0.037 & \\
\hline some college & -0.010 & 0.019 & & -0.043 & 0.019 & $* *$ & -0.015 & 0.031 & & -0.080 & 0.033 & $* *$ \\
\hline college & 0.057 & 0.019 & $* *$ & -0.032 & 0.019 & $*$ & 0.082 & 0.031 & $* *$ & -0.111 & 0.033 & $* *$ \\
\hline $1 \mathrm{kid}$ & -0.029 & 0.021 & & -0.023 & 0.021 & & -0.081 & 0.035 & $* *$ & -0.005 & 0.037 & \\
\hline 2 kids & -0.030 & 0.022 & & -0.018 & 0.022 & & -0.007 & 0.037 & & -0.034 & 0.039 & \\
\hline $3+$ kids & -0.049 & 0.028 & $*$ & -0.014 & 0.027 & & -0.047 & 0.046 & & -0.043 & 0.049 & \\
\hline 2 adults & 0.037 & 0.038 & & -0.029 & 0.038 & & -0.105 & 0.061 & $*$ & -0.007 & 0.065 & \\
\hline $3+$ adults & 0.017 & 0.044 & & -0.022 & 0.044 & & -0.075 & 0.072 & & -0.054 & 0.076 & \\
\hline midwest & 0.018 & 0.020 & & 0.053 & 0.020 & $* *$ & -0.023 & 0.033 & & -0.038 & 0.035 & \\
\hline south & 0.019 & 0.020 & & 0.042 & 0.020 & $* *$ & 0.019 & 0.032 & & -0.024 & 0.034 & \\
\hline west & -0.043 & 0.022 & $* *$ & 0.025 & 0.022 & & -0.055 & 0.036 & & -0.081 & 0.038 & $* *$ \\
\hline log likelihood & -31068 & & & -32366 & & & -11252 & & & -8919 & & \\
\hline \# obs & 23798 & & & 23775 & & & 9295 & & & 9405 & & \\
\hline Pseudo $\mathrm{R}^{2}$ & 0.01 & & & 0.05 & & & 0.01 & & & 0.04 & & \\
\hline$\chi^{2}(18)$ [pval] & 228 & {$[0.00]$} & & 158 & {$[0.00]$} & & 74 & {$[0.00]$} & & 401 & {$[0.00]$} & \\
\hline
\end{tabular}


Table 2: $\quad$ Efficiency: Cross-sectional Variation in Forecast Errors (ctd)

CAB Surveys, 1978-96

(5)

(6)

(7)

\begin{tabular}{|c|c|c|}
\hline$\varepsilon \mathrm{GY}=\mathrm{GY}^{\mathrm{r}}{ }_{2}-\mathrm{QGY}^{\mathrm{e}}{ }_{1}$ & $\varepsilon \Pi^{\mathrm{subj}}=\mathrm{Q} \Pi_{2}^{\mathrm{r}}-\mathrm{Q} \Pi_{1}^{\mathrm{e}}$ & $\varepsilon \Pi^{\mathrm{obj}}=\Pi_{12}-\mathrm{Q} \Pi_{1}^{\mathrm{e}}$ \\
\hline s.e. & coef. & coef. \\
\hline
\end{tabular}

\begin{tabular}{|c|c|c|c|c|c|c|c|c|c|}
\hline age & 0.754 & 0.147 & $* *$ & -0.029 & 0.050 & & -0.037 & 0.013 & $* *$ \\
\hline $\mathrm{age}^{2} / 100$ & -0.675 & 0.142 & $* *$ & 0.106 & 0.052 & $* *$ & 0.071 & 0.013 & $* *$ \\
\hline $\ln$ (income) & -5.291 & 0.705 & $* *$ & -0.370 & 0.221 & $*$ & 0.539 & 0.053 & $* *$ \\
\hline married & 2.111 & 2.106 & & -0.226 & 0.609 & & -0.165 & 0.123 & \\
\hline separated & -1.167 & 1.240 & & -0.067 & 0.416 & & 0.123 & 0.114 & \\
\hline nonwhite & -1.289 & 1.261 & & 0.126 & 0.535 & & -0.815 & 0.140 & $* *$ \\
\hline female & -1.360 & 1.075 & & 1.032 & 0.338 & $* *$ & -0.970 & 0.098 & $* *$ \\
\hline no high school & -0.970 & 1.169 & & -0.337 & 0.391 & & -0.396 & 0.112 & $* *$ \\
\hline some college & 1.234 & 0.816 & & -0.051 & 0.297 & & 0.269 & 0.073 & $* *$ \\
\hline college & 1.303 & 0.837 & & -0.336 & 0.250 & & 0.099 & 0.067 & \\
\hline $1 \mathrm{kid}$ & -0.634 & 0.963 & & -0.361 & 0.308 & & -0.152 & 0.086 & $*$ \\
\hline 2 kids & 0.194 & 0.962 & & 0.017 & 0.341 & & -0.319 & 0.086 & $* *$ \\
\hline $3+$ kids & -0.416 & 1.186 & & -0.304 & 0.431 & & -0.504 & 0.120 & $* *$ \\
\hline 2 adults & -0.007 & 1.945 & & 0.822 & 0.552 & & 0.097 & 0.108 & \\
\hline $3+$ adults & -1.093 & 2.173 & & 1.271 & 0.624 & $* *$ & 0.026 & 0.128 & \\
\hline midwest & 0.012 & 0.844 & & -0.532 & 0.295 & $*$ & 0.116 & 0.081 & \\
\hline south & -1.167 & 0.860 & & -0.215 & 0.306 & & 0.001 & 0.081 & \\
\hline west & -1.577 & 0.939 & $*$ & -0.531 & 0.328 & $*$ & -0.237 & 0.086 & $* *$ \\
\hline \# obs & 4856 & & & 8788 & & & 60695 & & \\
\hline $\mathrm{R}^{2}$ & 0.03 & & & 0.05 & & & 0.05 & & \\
\hline F [pval] & 5.52 & {$[0.00]$} & & 9.51 & {$[0.00]$} & & 35.3 & {$[0.00]$} & \\
\hline
\end{tabular}

Notes:

- This table estimates the systematic demographic components of forecast errors $\varepsilon$. using Equation (4).

In columns (1)-(4) the forecast errors are discrete and the estimation is by ordered probit.

$\mathrm{Q}_{1}^{\mathrm{e}}$ represents an expectation from interview one, $\mathrm{Q}_{2}^{\mathrm{r}}$ the corresponding realization from interview two. Except for inflation, $\mathrm{Q}=+1$ represents the better states (e.g. "better" or "good"), 0 the intermediate states, -1 the worse states.

Forecast errors are the difference between expectations and realizations: $\varepsilon=\left(\mathrm{Q}_{2}^{\mathrm{r}}-\mathrm{Q}_{1}^{\mathrm{e}}\right)$, with values in $\{-2,-1,0,1,2\}$. In columns (5)-(7) the forecast errors are constructed analogously but are continuous.

Estimation is by OLS, correcting the standard errors for heteroscedasticity.

- Coefficients on month dummies are not shown. The omitted categorical variables are: single, white, male head, high school graduate, no kids, one adult, northeast.

- $\chi^{2}$ and $\mathrm{F}$ test the joint significance of the demographic variables, with $\mathrm{p}$-values in the brackets.

$*=$ significant at the $10 \%$ level, $* *$ at $5 \%$.

- In columns (1)-(6) the sample is limited to households interviewed twice. Further, the same person (either head or spouse) must have been the respondent in both interviews.

In column (7), which uses the actual CPI $\Pi_{12}$ as the realization, the household may have been interviewed only once; and if interviewed twice, the respondent need not be the same person in both interviews. 
Table 3: $\quad$ Excess Sensitivity of Consumption to Sentiment

CEX, 1982-93

(1)

(2)

\begin{tabular}{l}
$\begin{array}{l}1 \text { st Stage } \mathrm{R}^{2} \\
{\left[\text { static } \mathrm{R}^{2}\right]}\end{array}$ \\
\hline
\end{tabular}
(3)

$\Delta \ln (\text { total consumption })_{t+1}$

coef. s.e.

independent variable

(row)

\begin{tabular}{|c|c|c|c|c|c|c|c|c|}
\hline \multirow[t]{2}{*}{ (1) } & $\mathrm{QFP}_{\mathrm{t}}^{\mathrm{r}}$ & 0.10 & -0.0134 & 0.0046 & $* *$ & -0.0210 & 0.0062 & $* *$ \\
\hline & & {$[.08]$} & & & & & & \\
\hline \multirow[t]{2}{*}{ (2) } & $\mathrm{QFP}_{\mathrm{t}}^{\mathrm{e}}$ & 0.11 & -0.0376 & 0.0103 & $* *$ & -0.0376 & 0.0141 & $* *$ \\
\hline & & {$[.10]$} & & & & & & \\
\hline \multirow[t]{2}{*}{ (3) } & $\mathrm{QBC}_{\mathrm{t}}$ & 0.13 & -0.0079 & 0.0050 & & -0.0109 & 0.0068 & $*$ \\
\hline & & {$[.02]$} & & & & & & \\
\hline \multirow[t]{2}{*}{ (4) } & $\mathrm{QBC}_{\mathrm{t}}$ & 0.06 & -0.0148 & 0.0042 & $* *$ & -0.0173 & 0.0056 & $* *$ \\
\hline & & {$[.03]$} & & & & & & \\
\hline \multirow[t]{2}{*}{ (5) } & QDurs $_{t}$ & 0.07 & -0.0049 & 0.0065 & & -0.0073 & 0.0086 & \\
\hline & & {$[.02]$} & & & & & & \\
\hline \multirow[t]{2}{*}{ (6) } & $\mathrm{QY}_{\mathrm{t}}^{\mathrm{e}}$ & 0.11 & -0.0190 & 0.0046 & $* *$ & -0.0278 & 0.0063 & $* *$ \\
\hline & & {$[.10]$} & & & & & & \\
\hline \multirow[t]{2}{*}{ (7) } & $\mathrm{QP}_{\mathrm{t}}^{\mathrm{e}}$ & 0.05 & 0.0049 & 0.0173 & & 0.0448 & 0.0243 & $*$ \\
\hline & & {$[.01]$} & & & & & & \\
\hline \multirow[t]{2}{*}{ (8) } & $\mathrm{QU}_{\mathrm{t}}^{\mathrm{e}}$ & 0.09 & 0.0132 & 0.0084 & & 0.0050 & 0.0112 & \\
\hline & & {$[.01]$} & & & & & & \\
\hline \multirow[t]{2}{*}{ (9) } & $\mathrm{QGY}_{\mathrm{t}}^{\mathrm{e}}$ & 0.08 & -0.0010 & 0.0007 & & -0.0021 & 0.0010 & $* *$ \\
\hline & & {$[.08]$} & & & & & & \\
\hline \multirow[t]{3}{*}{ (10) } & $\mathrm{Q} \Pi_{\mathrm{t}}^{\mathrm{e}}$ & 0.03 & 0.0017 & 0.0008 & $* *$ & 0.0032 & 0.0011 & $* *$ \\
\hline & & {$[.02]$} & & & & & & \\
\hline & \# obs & & 97993 & & & 97874 & & \\
\hline
\end{tabular}

Notes:

- This table tests for excess sensitivity of consumption to sentiment.

Each row-column cell in columns (2) and (3) represents a separate regression of Euler equation (3) in the CEX. The sentiment variables $Q$ are the predicted values from a first-step OLS regression of equation (1) in the CAB, with $\mathrm{R}^{2}$ as shown in column (1). The static $\mathrm{R}^{2}$ is for the same regression without time dummies and their interactions with demographic characteristics.

- Increases in Q represent worse states for inflation and unemployment (rows 7,8,10). In all other rows, increases in $\mathrm{Q}$ represent better states.

- Demographic control variables W and month dummies are not shown. Standard errors are corrected for heteroscedasticity and serial correlation by household, as well as the generated regressors.

$*=$ significant at the $10 \%$ level, $* *$ at $5 \%$. 
Table 4: Excess Sensitivity and Systematic Heterogeneity in Forecast Errors

CEX, 1982-93

(1)

(2)

$\Delta \ln (\text { nondurables })_{\mathrm{t}+1} \quad \Delta \ln (\text { total consumption })_{\mathrm{t}+1}$ coef. s.e.

independent variables

(row)

(1) $\mathrm{QFP}_{\mathrm{t}}^{\mathrm{e}}$

$$
\begin{aligned}
& \varepsilon F P\left(Q P^{r}{ }_{t+1}-Q^{2} P_{t}^{\mathrm{e}}\right) \\
& \# \text { obs }
\end{aligned}
$$

(2) $\mathrm{QBC}_{t}^{\mathrm{e}}$

$$
\varepsilon B C\left(Q^{2} C_{t+1}^{r}-Q^{e} C_{t}\right)
$$$$
\text { \# obs }
$$
(3) $\mathrm{QY}_{\mathrm{t}}^{\mathrm{e}}$
$\varepsilon \mathrm{Y}\left(\mathrm{QY}_{\mathrm{t}+1}^{\mathrm{r}}-\mathrm{QY}_{\mathrm{t}}^{\mathrm{e}}\right)$

$$
\text { \# obs }
$$

(4) $\mathrm{QP}_{\mathrm{t}}^{\mathrm{e}}$

$$
\begin{gathered}
\varepsilon P\left(\mathrm{QP}_{\mathrm{t}+1}^{\mathrm{r}}-\mathrm{QP}_{\mathrm{t}}^{\mathrm{e}}\right) \\
\# \text { obs }
\end{gathered}
$$

(5) $\mathrm{QGY}_{\mathrm{t}}^{\mathrm{e}}$

$$
\varepsilon G Y\left(Q G Y^{\mathrm{r}}{ }_{\mathrm{t}+1}-\mathrm{QGY}_{\mathrm{t}}^{\mathrm{e}}\right)
$$$$
\text { \# obs }
$$
(6) $\mathrm{Q} \Pi_{\mathrm{t}}^{\mathrm{e}}$

$$
\varepsilon \Pi\left(\mathrm{Q} \Pi_{\mathrm{t}+1}^{\mathrm{r}}-\mathrm{Q} \Pi_{\mathrm{t}}^{\mathrm{e}}\right)
$$

\begin{tabular}{|c|c|c|c|c|}
\hline-0.0010 & 0.0015 & & -0.0001 & 0.0020 \\
\hline \multirow[t]{2}{*}{-0.0024} & 0.0013 & $*$ & -0.0035 & 0.0018 \\
\hline & 29528 & & & 29504 \\
\hline
\end{tabular}$$
\text { \# obs }
$$

$\begin{array}{llllll}-0.0374 & 0.0105 & * * & -0.0375 & 0.0142 & * * \\ 0.0186 & 0.0075 & * * & 0.0105 & 0.0101 & \\ & 97993 & & & 97874\end{array}$

$\begin{array}{lllll}-0.0065 & 0.0089 & & 0.0091 & 0.0119 \\ 0.0186 & 0.0072 & * * & 0.0115 & 0.0100 \\ & 97993 & & & 97874\end{array}$

$\begin{array}{lllll}-0.0031 & 0.0098 & & -0.0087 & 0.0135 \\ 0.0269 & 0.0158 & * & 0.0255 & 0.0219 \\ & 29528 & & & 29504\end{array}$

$\begin{array}{llll}0.0020 & 0.0342 & 0.0318 & 0.0450 \\ -0.0124 & 0.0148 & -0.0033 & 0.0200 \\ & 29528 & & 29504\end{array}$

$\begin{array}{llllll}-0.0047 & 0.0017 & * * & -0.0045 & 0.0023 & * * \\ 0.0014 & 0.0004 & * * & 0.0010 & 0.0005 & * * \\ & 30292 & & & 30255 & \end{array}$

Notes:

- See notes to Table 3.

- This table tests whether the excess sensitivity in Table 3 is due to systematic heterogeneity in forecast errors.

Each row-column cell represents a separate regression of Euler equation (3) in the CEX.

The forecast errors $\varepsilon=\mathrm{Q}_{\mathrm{t}+1}^{\mathrm{r}}-\mathrm{Q}_{\mathrm{t}}^{\mathrm{e}}$ are first estimated in the CAB using OLS regressions of eq. (4), then imputed in the CEX.

- Demographic control variables $\mathrm{W}$ and month dummies are not shown. Standard errors are corrected for heteroscedasticity and serial correlation by household, as well as the generated regressors.

$*=$ significant at the $10 \%$ level, ** at $5 \%$. 